\title{
Loss-of-function of sox 3 causes follicle development retardation and reduces fecundity in zebrafish
}

\author{
Qiang Hong, Cong Li, Ruhong Ying, Heming Lin, Jingqiu Li, Yu Zhao, Hanhua Cheng ${ }^{\bowtie}$, Rongjia Zhou ${ }^{\bowtie}$ \\ Hubei Key Laboratory of Cell Homeostasis, College of Life Sciences, Wuhan University, Wuhan 430072, China \\ $\triangle$ Correspondence: hhcheng@whu.edu.cn (H. Cheng), rjzhou@whu.edu.cn (R. Zhou) \\ Received July 10, 2018 Accepted November 21, 2018
}

\begin{abstract}
Folliculogenesis is essential for production of female gametes in vertebrates. However, the molecular mechanisms underlying follicle development, particularly apoptosis regulation in ovary, remain elusive. Here, we generated sox 3 knockout zebrafish lines using CRISPR/ Cas9. sox3 knockout led to follicle development retardation and a reduced fecundity in females. Comparative analysis of transcriptome between so $3^{-l-}$ and wild-type ovaries revealed that Sox3 was involved in pathways of ovarian steroidogenesis and apoptosis. Knockout of sox 3 promoted follicle apoptosis and obvious apoptosis signals were detected in somatic cells of stages III and IV follicles of $50 \times 3^{-l-}$ ovaries. Moreover, Sox 3 can bind to and activate the promoter of cyp19a1a. Up-regulation of Cyp19a1a expression promoted 17 $\beta$-estradiol synthesis, which inhibited apoptosis in follicle development. Thus, Sox3 functions as a regulator of Cyp19a1a expression, via $17 \beta-E 2$ linking apoptosis suppression, which is implicated in improving female fecundity.
\end{abstract}

KEYWORDS Sox3, follicle development, apoptosis, Cyp19a1a, zebrafish

\section{INTRODUCTION}

In the vertebrate ovary, follicles are the functional units for oogenesis, which contain oocytes, granulosa cells and theca

Qiang Hong and Cong Li are co-first authors.

Electronic supplementary material The online version of this article (https://doi.org/10.1007/s13238-018-0603-y) contains supplementary material, which is available to authorized users. cells. The communication between oocytes and granulosa cells is essential for oocyte development (Eppig, 2001). Granulosa cells can provide some substances, including cholesterol, specific amino acids and nutrients for oocyte development (Su et al., 2009), while oocytes secrete some paracrine factors, such as BMP15 (bone morphogenetic protein 15) and GDF9 (growth differentiation factor 9) to regulate granulosa cells development (Su et al., 2004; Su et al., 2009). Hence, the bidirectional communication between oocytes and somatic cells is important for oogenesis. Studies have shown that autophagy of ovarian somatic cells is involved in regulation of follicular development by maintaining cell homeostasis (Yuan et al., 2015), while apoptosis of granulosa cells is pivotal for follicular development through atresia of many early follicles to ensure growth and maturation of some dominant follicles (Matsuda et al., 2012). However, the molecular mechanisms connecting apoptosis in ovary to follicle development remain largely unknown. Identification of key regulators of apoptosis and relevant pathways is important for understanding ovarian functions.

In follicle development, some factors and relevant pathways involved in both pro- and anti-apoptotic have been identified. FSH inhibited FoxO1-dependent apoptosis by coordinating the PKA-PI3K-AKT-FoxO1 axis and FoxO1FoxO1 positive feedback in mouse granulosa cells (Shen et al., 2014). FGF-2 can inhibit apoptosis and promote follicle growth in culture in vitro in sheep (Santos et al., 2014). Upregulated apoptosis was associated with a decrease in number of vitellogenic follicles when the physiochemical waters parameters were unfavorable in fish (Thome et al., 2012). BCL2 family members, which included pro-apoptotic (e.g., Bax and Bok) and anti-apoptotic (e.g., Bc/2 and Mcl1) genes, were another kind of apoptosis regulators during follicle development (Perez et al., 1999; Hutt, 2015). Bcl2 


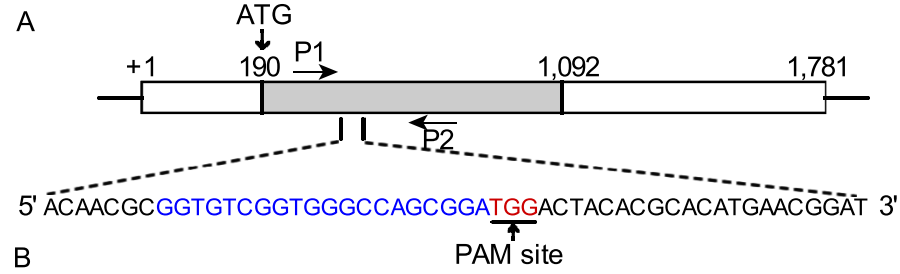

WT ACAACGCGGTGTCGGTGgGCCAGCGGATGGACTACACGCACATGAACGGAT sox $3^{\text {f7 }}$ ACAACGCGGTGTCGGTGGG $\cdots \cdots \cdot$ ATGGACTACACGCACATGAACGGAT $(-7)$ $\operatorname{sox}^{740}$ ACAACGCGG $\ldots \ldots \ldots \ldots \ldots \ldots \ldots \ldots \ldots \ldots \ldots \ldots \ldots \ldots \ldots \ldots \ldots \ldots \ldots$ C ACAACGCGGTGTCGGTGGG'ATGGACTACACGCACATGAACGGAT $\operatorname{sox} 3^{\text {f7 }}$

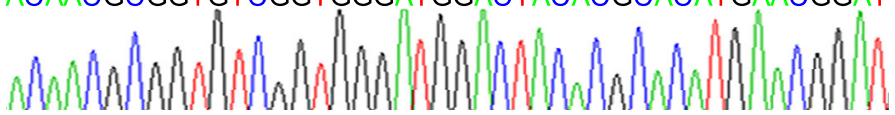
ACAACGCGG'A

sox3 $3^{40}$

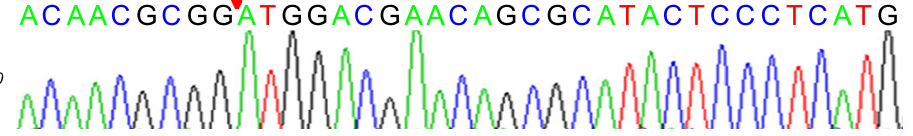

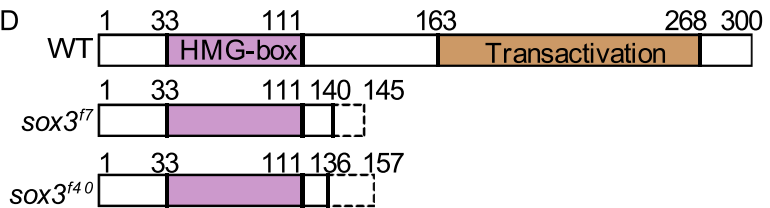

E sox $3^{\text {t7 }}$ typing

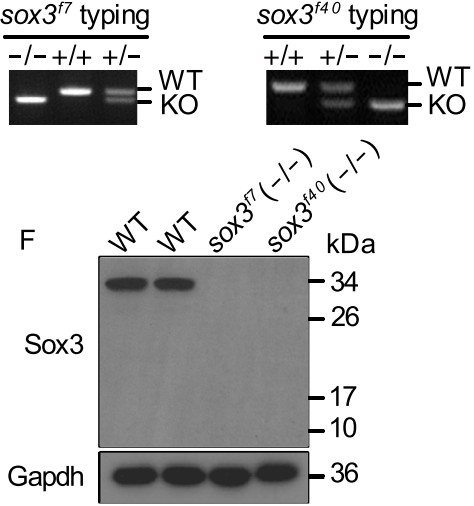

Figure 1. Generation of sox3 mutant strains of zebrafish using CRISPR/Cas9 system. (A) Schematic representation of gRNA targeting the sox3 locus. The translation start codon ATG was indicated by an arrow. The gRNA (blue) was designed to target open reading frame (ORF) (gray). The PAM (protospacer adjacent motif) site was underlined in red. P1 and P2 were primers for genotyping. (B) Nucleotide sequence alignments of the two mutant sites $\left(\operatorname{sox} 3^{f 7}\right.$ and $\operatorname{sox} 3^{f 40}$ ) with WT sequence. The deleted sequences were indicated in dotted lines. One had a 7-bp deletion, the other had a 40-bp deletion. (C) DNA sequencing of sox3 mutant alleles of both $\operatorname{sox} 3^{f 7}$ and $\operatorname{sox} 3^{f 40}$ strains. The red arrows indicated the deleted positions. (D) Schematic diagram of protein coding regions of wide type Sox3 and two predicted truncated mutants. The conserved domains (HMG-box and transactivation) were indicated in boxes (solid lines). Frameshift sequences were showed in boxes with dash lines. The numbers refer to the amino acid positions. (E) PCR analysis to determine genotypes of offsprings from heterozygote intercrosses in two KO strains. The KO band (287 bp of sox $3^{f 7}$ and $254 \mathrm{bp}$ of sox $^{\mathrm{f} 40}$ ) can be distinguished from WT band (294 bp). Primer sequences and PCR conditions were listed in Table S1. (F) Western blot analysis of Sox3 expression. Ovary extracts from adult zebrafish were subjected to Western blots to detect Sox3 expression. The band of Sox3 protein was present in $33 \mathrm{kDa}$ in WT zebrafish. Gapdh was used as an internal control.

knockout led to aberrant follicle development in adult mice (Ratts et al., 1995), while overexpression of $B c / 2$ resulted in decreased follicle apoptosis (Hsu et al., 1996). However, Bcl2 knockout did not alter neonatal ovarian histology (Jones and Pepling, 2013). In addition, estradiol and microRNA can inhibit granulosa cell apoptosis and promote follicular development (Liu et al., 2014b; Qiu et al., 2014). Despite these progresses, the molecular mechanisms of ovarian apoptosis and its influence on follicle development remain elusive.

Zebrafish (Danio rerio), as an excellent model organism, has two distinct sexes in adults, but they are juvenile hermaphrodites (Takahashi, 1977). All the gonads of earlystage (3 weeks ago) are undifferentiated gonads, called "bipotential juvenile ovaries" (Takahashi, 1977; Wang et al., 2007b). From 20 days post fertilization (dpf), some of the bipotential ovaries continue to become ovaries, the others undergo an apoptosis process and finally develop into testes. About $40 \mathrm{dpf}$, their sexes can be distinguished according to gonadal histology (Uchida et al., 2002; Orban et al., 2009). Molecular mechanisms of sex determination in zebrafish remain elusive. Domesticated zebrafish strains lack sex-linked loci, although natural strains have WZ/ZZ sex chromosomes (Wilson et al., 2014). A number of genes involved in gonadal differentiation have been identified in zebrafish, which include female sex-biased genes: mett/3 (methyltransferase like 3) (Xia et al., 2018), cyp19a1a (cytochrome P450, family 19, subfamily A, polypeptide 1a) (Lau et al., 2016; Yin et al., 2017), nrOb1 (nuclear receptor subfamily 0 group B member 1) (Chen et al., 2016), fox/2a (forkhead box L2a), foxl2b (forkhead box L2b) (Yang et al., 2017), bmp15 (bone morphogenic protein 15) (Dranow et al., 2016) and fgf24 (fibroblast growth factor 24) (Leerberg et al., 2017), and male sex-biased genes: dmrt1 (doublesex and mab-3 related transcription factor 1) (Guo et al., 2005; Lin et al., 2017; Webster et al., 2017), amh (anti-Mullerian hormone) (Lin et al., 2017), sox9a (sex-determining region Y-box 9a) (Sun et al., 2013) and ar (androgen receptor) (Crowder et al., 2018). As lack of morphological sex chromosome in zebrafish, molecular mechanisms of sex determination and differentiation are probably multigenic (Liew et al., 2012) and key genes remain to be identified.

Sox3 (sex-determining region Y-box 3), belonged to the SOX family, is an ancestral precursor of Sry (Foster and 
Graves, 1994), which is a key male sex-determining gene in mammals (Sinclair et al., 1990; Koopman et al., 1991). In transgenic mice, overexpression of Sox3 led to a complete XX male sex reversal phenotype (Sutton et al., 2011), while loss-of-function mutations showed that it was not required for sex determination, but important for oocyte development, testis differentiation and gametogenesis (Weiss et al., 2003). Nevertheless, genomic rearrangements, de novo duplication or interchromosomal insertional translocation at xq26.3 regulatory region of SOX3 caused XX male sex reversal in humans (Sutton et al., 2011; Moalem et al., 2012; Haines et al., 2015). Sox3 was also required for formation of the hypothalamo-pituitary axis in mice (Rizzoti et al., 2004), the neurogenesis and neural tube in chicken (Bylund et al., 2003) and zebrafish (Dee et al., 2008; Gou et al., 2018a; Gou et al., 2018b). In addition, in medaka (Oryzias dancena), sox $3^{Y}$ was a male-determining factor (Takehana et al., 2014). However, sox3 had more important role in oogenesis than in spermatogenesis in grouper (Epinephelus coioides) (Yao et al., 2007) and Japanese eel (Anguilla japonica) (Jeng et al., 2018). Thus, functions of sox3 are complex and multiple across vertebrates.

In the present study, we first generated sox3 knockout zebrafish lines using CRISPR/Cas 9 and found that sox 3 knockout led to follicle development retardation and a reduced fecundity in females. Transcriptome analysis revealed that apoptosis signaling pathway was up-regulated and ovarian steroidogenesis was down-regulated in sox $3^{-1-}$ ovaries in comparison with wild type ovaries. Knockout of sox3 caused follicle apoptosis. Furthermore, we demonstrated that Sox 3 can promote $17 \beta-E 2$ synthesis by binding to and activating the cyp19a1a promoter, which led to apoptosis decrease in follicle development. Hence, we revealed Sox3 as a regulator of Cyp19a1a expression, via $17 \beta-E 2$ linking apoptosis suppression in ovary development, which is implicated in improving female fecundity.

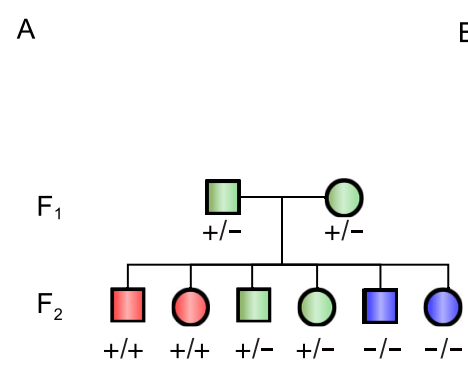

\section{B}
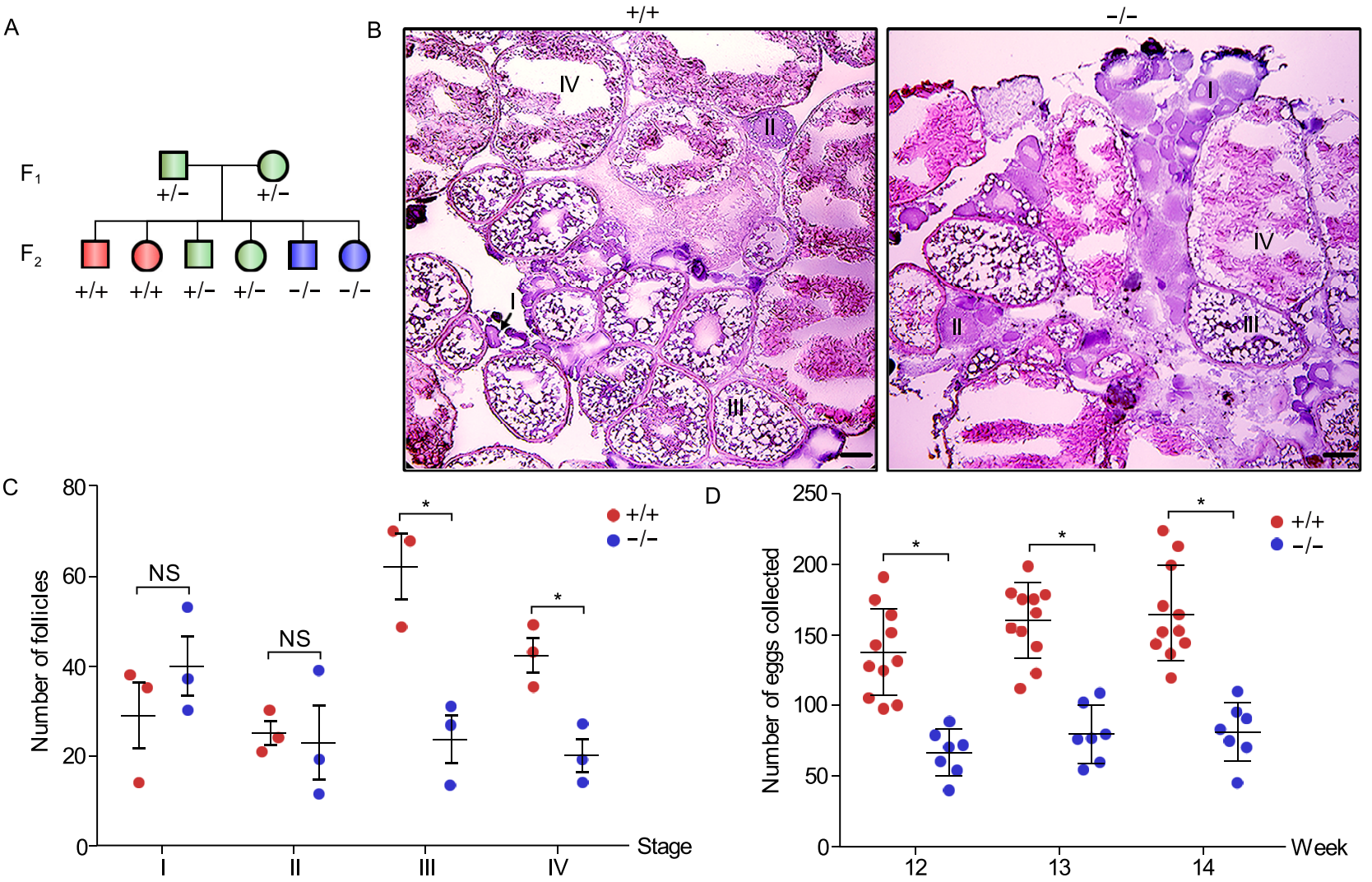

Figure 2. Knockout of sox3 leads to follicle development retardation and a reduced fecundity in female zebrafish. (A) Schematic diagram of heterozygote incrosses. All data are from the progeny derived from heterozygote incrosses. WT, +/+; heterozygotes, +/-; homozygotes, -/-. (B) Histological analysis of adult ovaries of $s o x 3^{+/+}$and $\operatorname{sox} 3^{-/-}$by H.E. staining. I, primary growth stage; II, cortical alveolus stage; III, early-vitellogenic stage; IV, late-vitellogenic stage. Scale bar, $50 \mu \mathrm{m}$. (C) Statistic analysis of different stages of follicles from 10 sections for each ovary of sox $3^{+/+}$and $\operatorname{sox} 3^{-1-}$ ( $n=3$ fish per genotype). Data represent means \pm SEM. T-test was performed. ${ }^{\star} P<0.05 ;{ }^{\star \star} P<0.01$. NS, not significant. (D) Impaired fecundity in sox $3^{-/-}$. Statistical analysis of the numbers of eggs produced by sox $3^{-/-}$incrosses or sox $3^{+/+}$incrosses at 12-, 13- and 14-week. Data represent means \pm SEM. T-test was performed. ${ }^{*} P<0.05$. 


\section{RESULTS}

\section{Generation of sox3 mutant lines using CRISPR/Cas9}

To explore the function of sox 3 in ovary development in zebrafish, sox3 knockout zebrafish lines were first generated using CRISPR/Cas9 technology. We used a CRISPR design web tool (http://crispr.mit.edu/) to design gRNA targeted the $5^{\prime}$ upstream of coding region (Fig. 1A). Two independent sox3 mutant lines were established: one had a 7-bp deletion (sox $3^{f 7}$ ) and the other had a 40-bp deletion $\left(\operatorname{sox} 3^{f 40}\right.$ ) (Fig. $1 \mathrm{~B}$ and $\left.1 \mathrm{C}\right)$. Both induced frame-shift mutations (Fig. 1D). Sox3 has a DNA-binding domain and a transactivation domain. To determine loss of function in both $s o x 3^{f 7}$ and $s o x 3^{f 40}$, deletion mapping and Gal4 dualluciferase reporter assay system were performed, which revealed that the transactivation domain is essential for transcriptional activation of Sox3 (Figs. S1A and 1B). To characterize both $s 0 \times 3^{f 7}$ and $s 0 \times 3^{f 40}$ zebrafish at the molecular level, quantitative real-time PCR was performed, which revealed that sox 3 was significantly reduced in sox3 knockout ovaries compared to wild type ovaries (Fig. S2), suggesting transcript destabilization and degradation of Sox $3^{\mathrm{f7}}$ and $\mathrm{Sox}^{\mathrm{f} 40}$ in the mutants by nonsense-mediated mRNA decay (NMD) due to premature termination codons (Baker and Parker, 2004; Popp and Maquat, 2016). Homozygotes $\left(\right.$ so $\times 3^{-/-}$) were produced by incross of the sox3 $3^{+/-}$zebrafish, which can be identified by PCR (Fig. 1E). Western blot analysis showed complete absence of Sox3 protein in the both mutant lines (Fig. 1F). Thus, both mutant lines had lost the function of Sox3. In order to determine the off-target effects, we aligned the target sequence to the zebrafish genome to search for all the potential off-target sites using the on-line tool (http://crispr. mit.edu). The results indicated that no off-target mutagenesis was detected in the two mutant lines (Fig. S3A-C). These data suggested that Sox3 was disrupted with no protein expression in the two knockout lines.

\section{Sox3 is required for follicle development and fecundity in zebrafish}

To investigate roles of sox 3 in follicle development, both so $\times 3^{+/+}$and so $3^{-/-}$from sox $3^{+/-}$incross were used for histological analysis of different stages of follicles. Statistical analysis showed less follicles of early-vitellogenic stage (III) and late-vitellogenic stage (IV) in sox $3^{-/-}$ovaries than those in wild-type ovaries. The follicle number of primary growth stage (I) and cortical alveolus stage (II) had no significant difference between so $3^{+/+}$and sox $3^{-/-}$ovaries (Fig. 2A-C). These results indicated that follicle development was retarded in the sox $3^{-1-}$ ovaries compared to wild type ovaries. Furthermore, the average number of eggs produced by females from sox $3^{-/-}$incrossed was significantly less than that from sox3 $3^{+/+}$incrossed at 12-, 13- and 14-week (Fig. 2D). Taken together, these results suggested that sox 3
Figure 3. Transcriptome analysis of adult ovaries from sox $3^{+/+}$and $\operatorname{sox}^{-l-}$. (A) Hierarchical clustering indicated the differentially expressed genes (DEGs) and their expression levels in $\mathrm{sox}^{+/+}$and $\mathrm{sox}^{-/-}$ovaries (fold change $>1.4 \&$ FDR $<0.05$ ). Colors indicated relative expression compared to the mean value. The scale bar indicated $\log _{2}(\mathrm{FPKM})$. FPKM, fragments per kilo bases per million fragments. (B) Scatter plot chart indicated the DEGs between so $^{+/ /+}$and so $^{-1 /-}$ ovaries. Yellow and blue dots represented up-regulated $(1,740,8.44 \%)$ and down-regulated $(2,196,10.66 \%)$ genes in sox $3^{-1-}$ ovaries, while the black dots represented equally expressed genes between sox $3^{+/+}$and sox $3^{-/-}$ovaries. (C) Volcano chart indicated the DEGs between so $3^{+/+}$and so $^{-1-}$ ovaries. Red dots represented up-regulated or downregulated genes, while the black dots represented equally expressed genes between sox $3^{+/+}$and $\operatorname{sox} 3^{-/-}$ovaries. FDR, false discovery rate. (D) Gene Ontology (GO) analysis of DEGs between sox $3^{+/+}$and $s o \times 3^{-/-}$ovaries. $X$-axis indicated the catalogs of cellular component, molecular function and biological process. Y-axis on the left indicated the number of genes in a category as a percent of the total number of DEGs and the actual numbers of DEGs are shown on the right. (E) KEGG analysis of up-regulated DEGs. The numbers represented the actual number of DEGs that were classified in a particular pathway. $\mathrm{X}$-axis indicated the percentage of the DEGs in the pathway. (F) KEGG analysis of downregulated DEGs. The numbers represented the actual number of DEGs that were classified in a particular pathway. X-axis indicated the percentage of the DEGs in the pathway.

knockout leads to follicle development retardation and a reduced fecundity in female zebrafish.

\section{Sox3 deletion influences pathways of ovarian steroidogenesis and apoptosis}

To examine possible pathways of Sox3 regulation in ovary development, we performed transcriptome sequencing and analysis of $\mathrm{sox}^{+/+}$and sox $3^{-/-}$ovaries (Fig. S4A-C and Tables S2-4). Over 3930 differentially expressed genes (DEGs) were detected, based on both fold change $(F C)>1.4$ and false discovery rate $(\mathrm{FDR})<0.05$, in the sox $3^{-/-}$ovaries in comparison with wild type ovaries, of them $8.44 \%$ (1740) were up-regulated and $10.66 \%(2,196)$ were down-regulated (Fig. 3A-C). Gene Ontology (GO) analysis of DEGs between sox $3^{+/+}$and sox $^{-/-}$ovaries showed that the DEGs were mainly enriched in the binding and catalytic activity in molecular function, and cellular process, death, metabolic process and reproduction in biological process (Fig. 3D). Kyoto Encyclopedia of Genes and Genomes (KEGG) analysis showed that the apoptosis signaling pathway was significantly up-regulated and ovarian steroidogenesis was significantly down-regulated in $50 \times 3^{-1-}$ ovaries in 

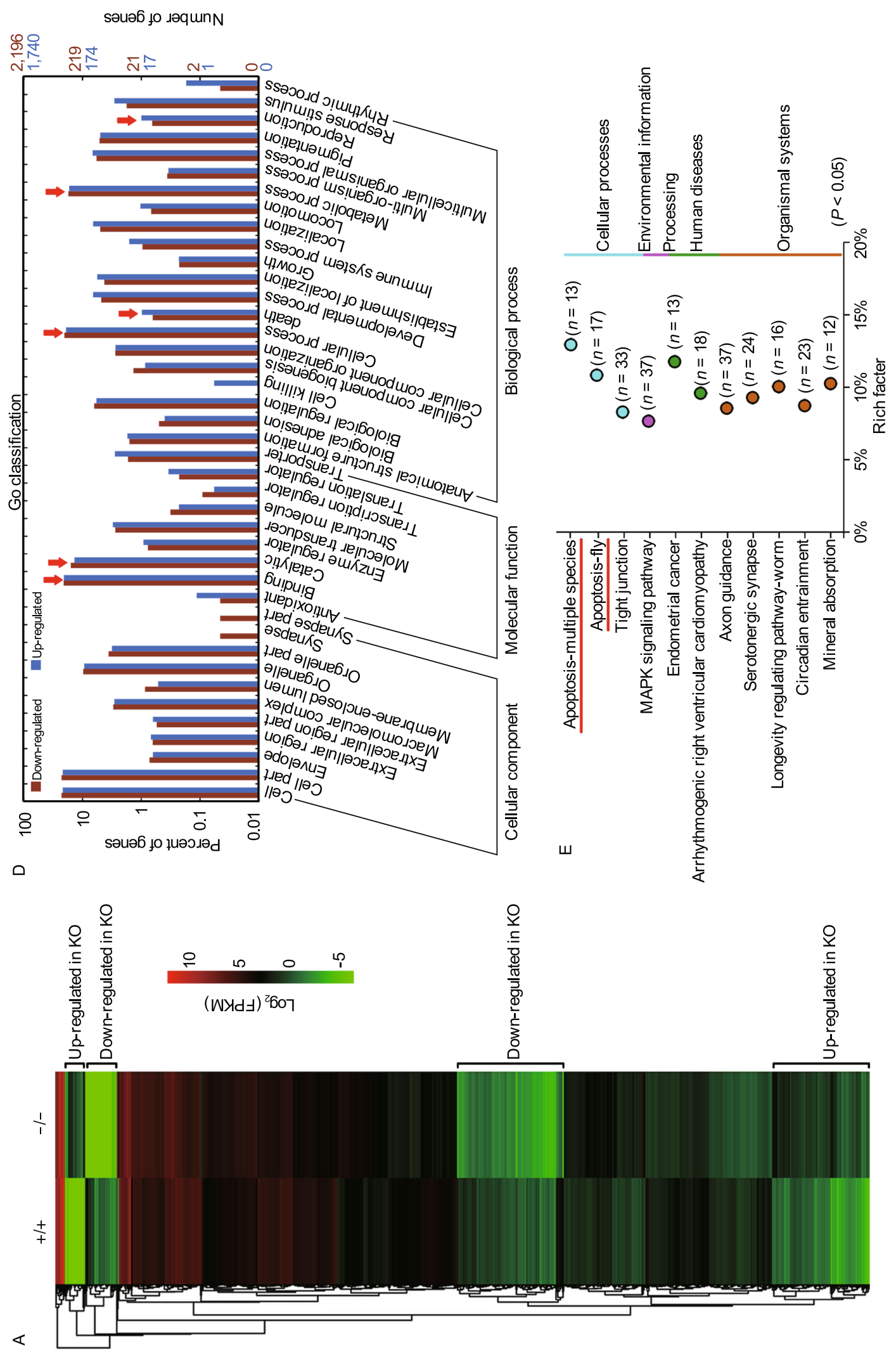


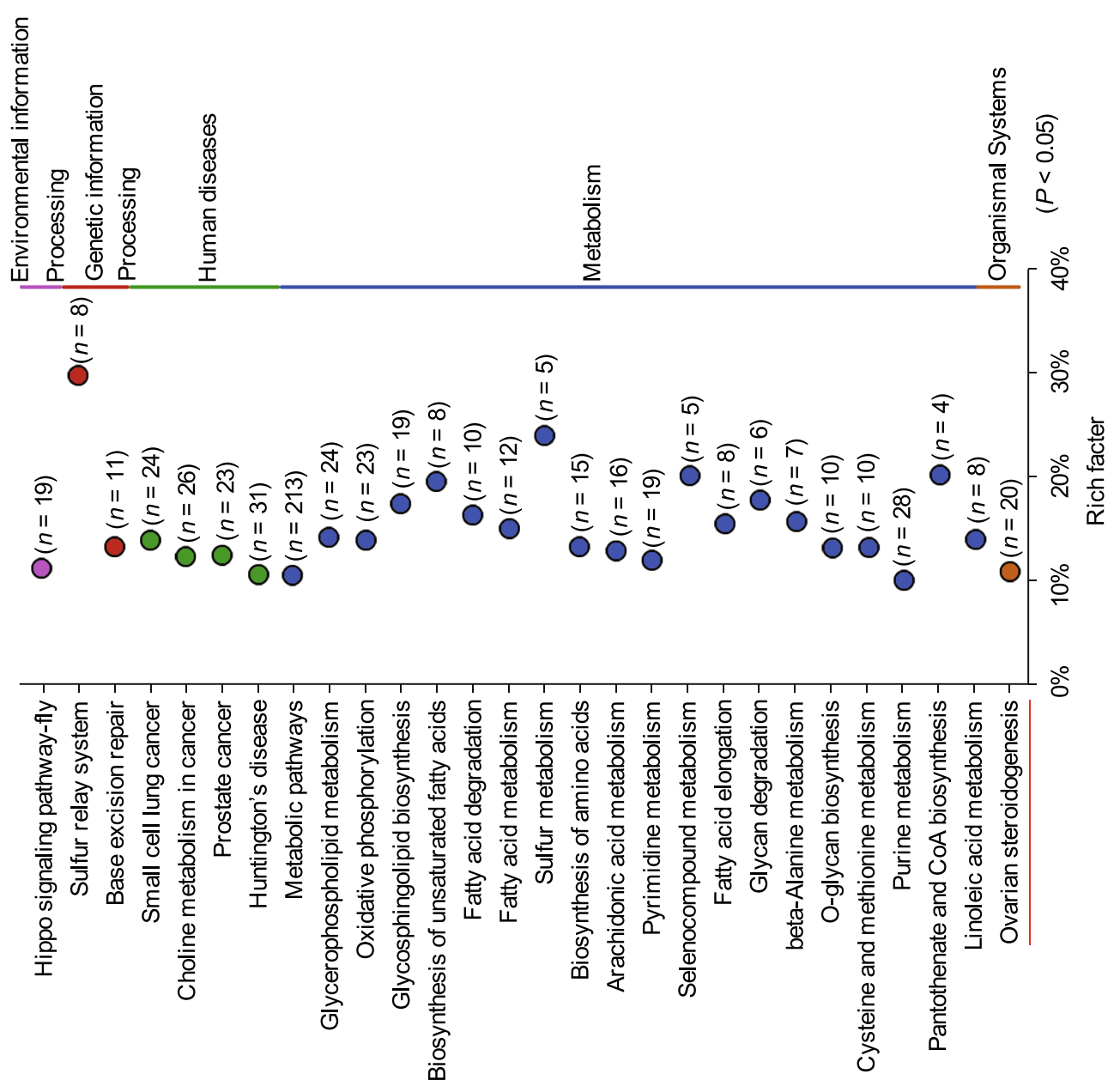

$\leftarrow$
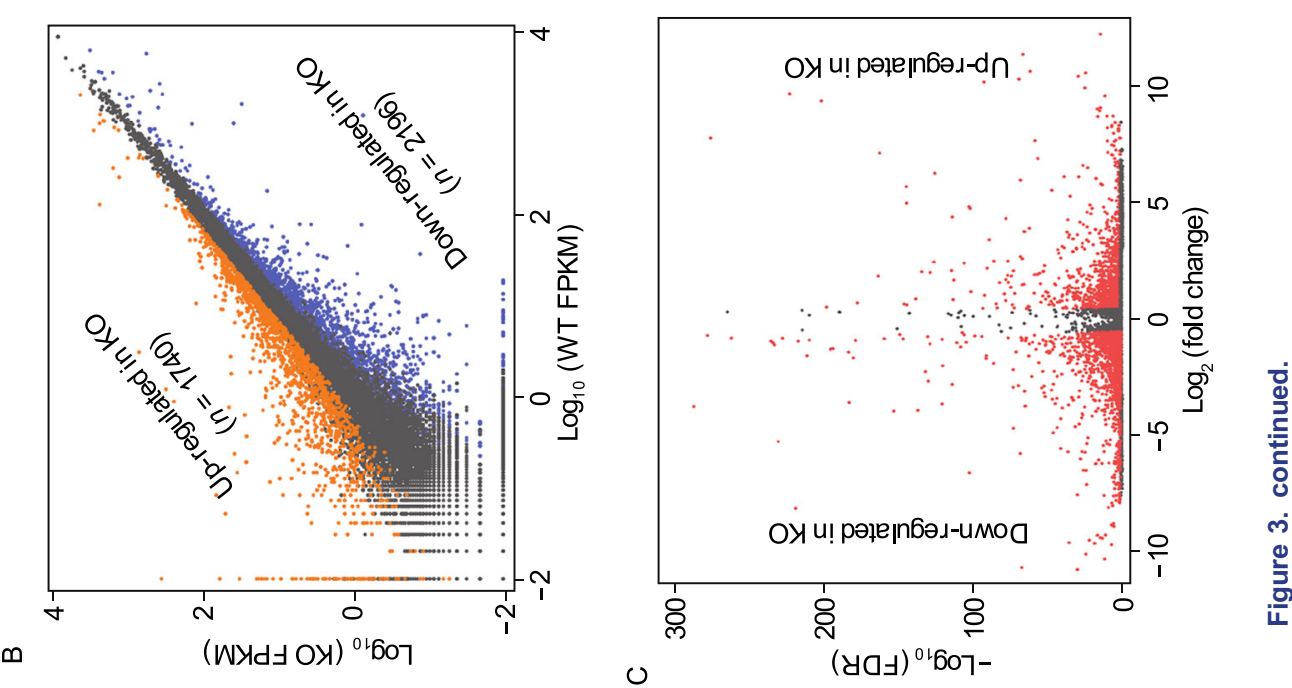


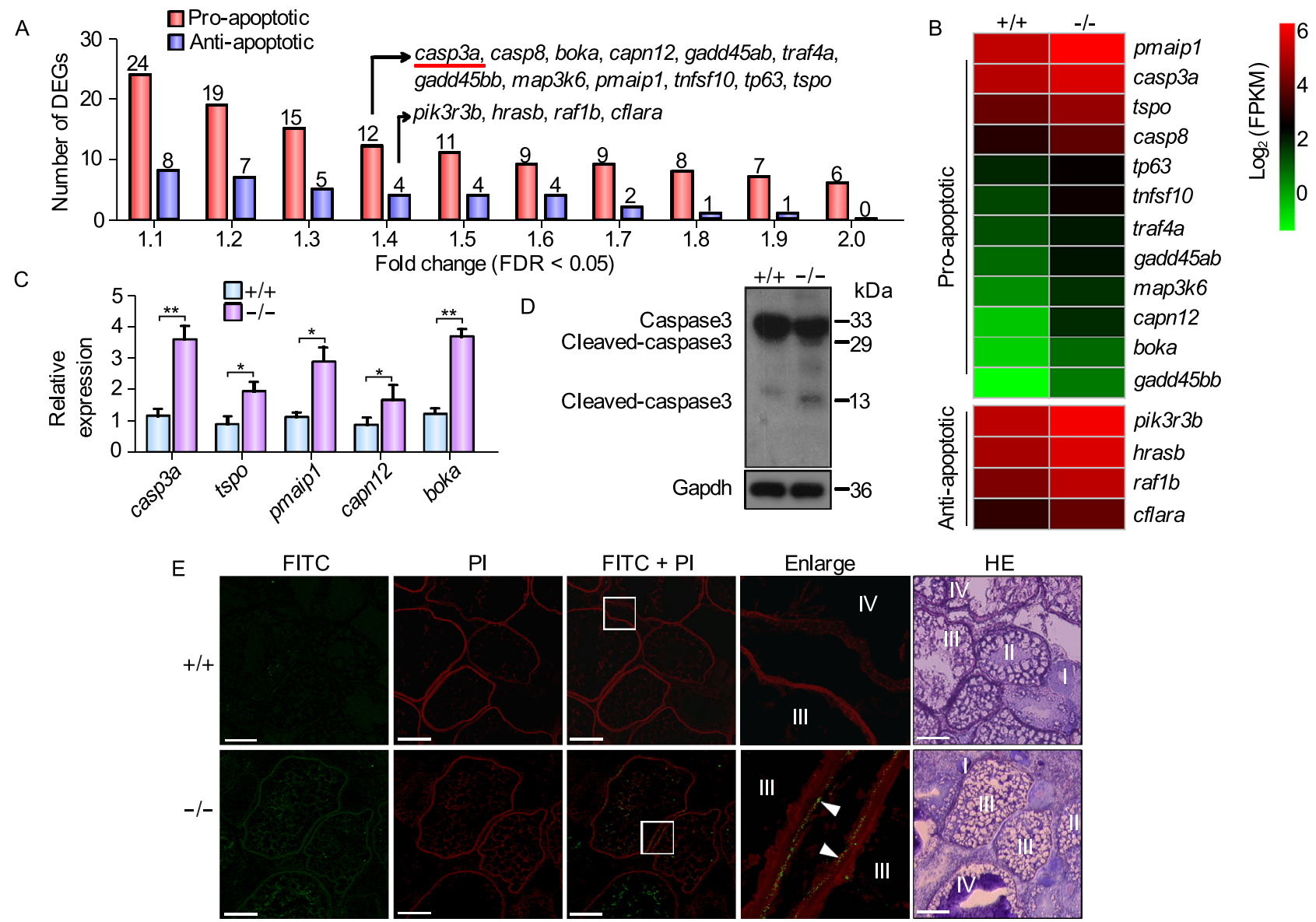

Figure 4. Up-regulated apoptosis in the sox $3^{-1-}$ ovaries in comparison with wild type ovaries. (A) Statistical analysis of the

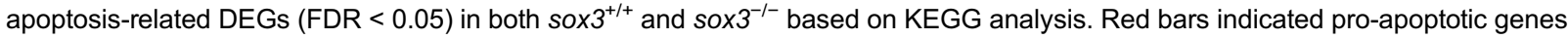
and blue bars represented anti-apoptotic genes. The genes with fold change of 1.4 were listed. (B) Hierarchical clustering indicated the expression levels of apoptosis-related DEGs between sox $3^{+/+}$and $s o x 3^{-/-}$ovaries. (C) Quantitative real-time PCR analysis of selected genes to validate the DEGs from RNA-seq data. The transcript levels were related to $\beta$-actin expression. Relative level, $2^{-\Delta \Delta \mathrm{Ct}}$. T-test was performed. ${ }^{*} P<0.05$; ${ }^{* \star} P<0.01$. (D) Western blot analysis showed that cleaved-caspase 3 were up-regulated in the sox $^{-1-}$ ovaries in comparison with the wild type ovaries. Gapdh was used as an internal control. (E) TUNEL analysis. In follicles of stages III and IV, obvious signals (FITC-labeled, green) were observed in somatic cells (theca cells and granulosa cells) (white arrowheads) of $\mathrm{sox}^{-/-}$ovaries. The nuclei were stained by PI (red). The enlarged images originated from the white squares. The ovaries sections were stained by H.E. and showed on the right. Scale bar: $100 \mu \mathrm{m}$.

comparison with wild type ovaries (Fig. 3E and 3F). These data suggested that Sox3 probably regulated ovary development through pathways of ovarian steroidogenesis and apoptosis.

Disrupted pathway of $17 \beta-E 2$ synthesis and upregulated apoptosis in the sox $3^{-1-}$ ovaries

To further explore molecular mechanism of Sox3-regulated apoptosis in ovary, transcriptome and quantitative real-time PCR analysis were then performed. Pro-apoptotic DEGs were significantly up-regulated in sox 3 knockout ovaries compared to wild type ovaries, such as casp3a (caspase 3 , apoptosis-related cysteine peptidase a), pmaip1 (phorbol12-myristate-13-acetate-induced protein 1) and tspo (translocator protein), while a few of anti-apoptotic DEGs were also up-regulated in sox 3 knockout ovaries compared to wild type ovaries (Fig. 4A-C). Western blot analysis showed that cleaved-caspase 3 was up-regulated in sox 3 knockout ovaries in comparison with wild type (Fig. 4D). TUNEL analysis further confirmed the up-regulated apoptosis in the sox $3^{-1-}$ ovaries. In particular, in follicles of stages III and IV, obvious FITC-labeled signals were detected in somatic cells (theca cells and granulosa cells) of so $3^{-1-}$ ovaries (Fig. 4E). These results indicated that knockout of sox3 promoted follicle apoptosis in zebrafish ovary. 


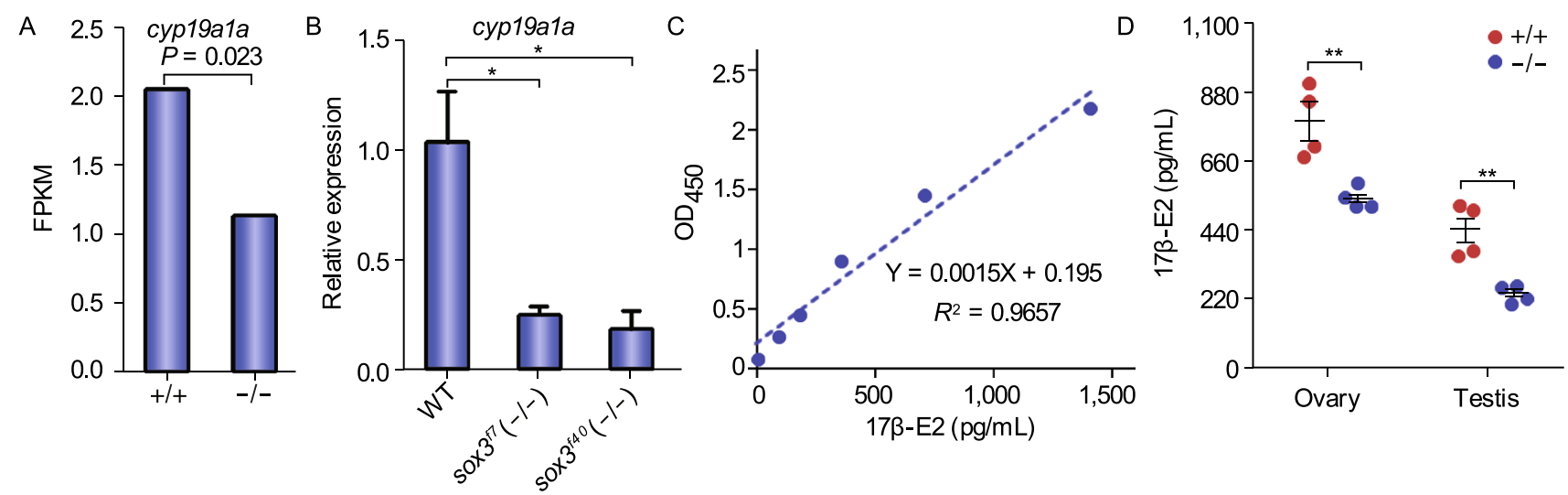

E
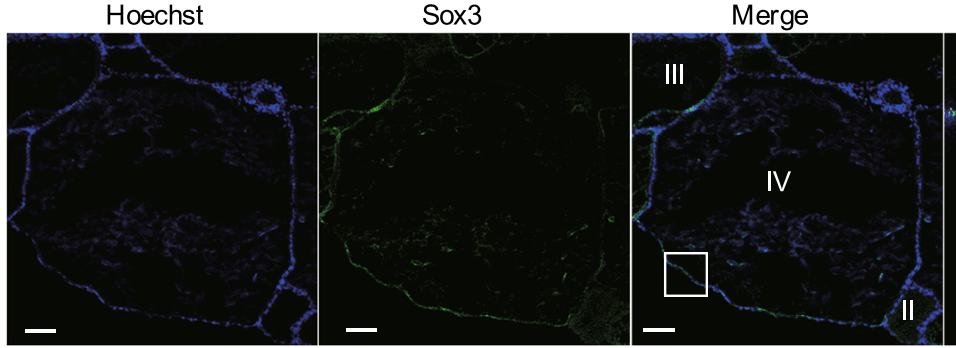

Enlarge

Control

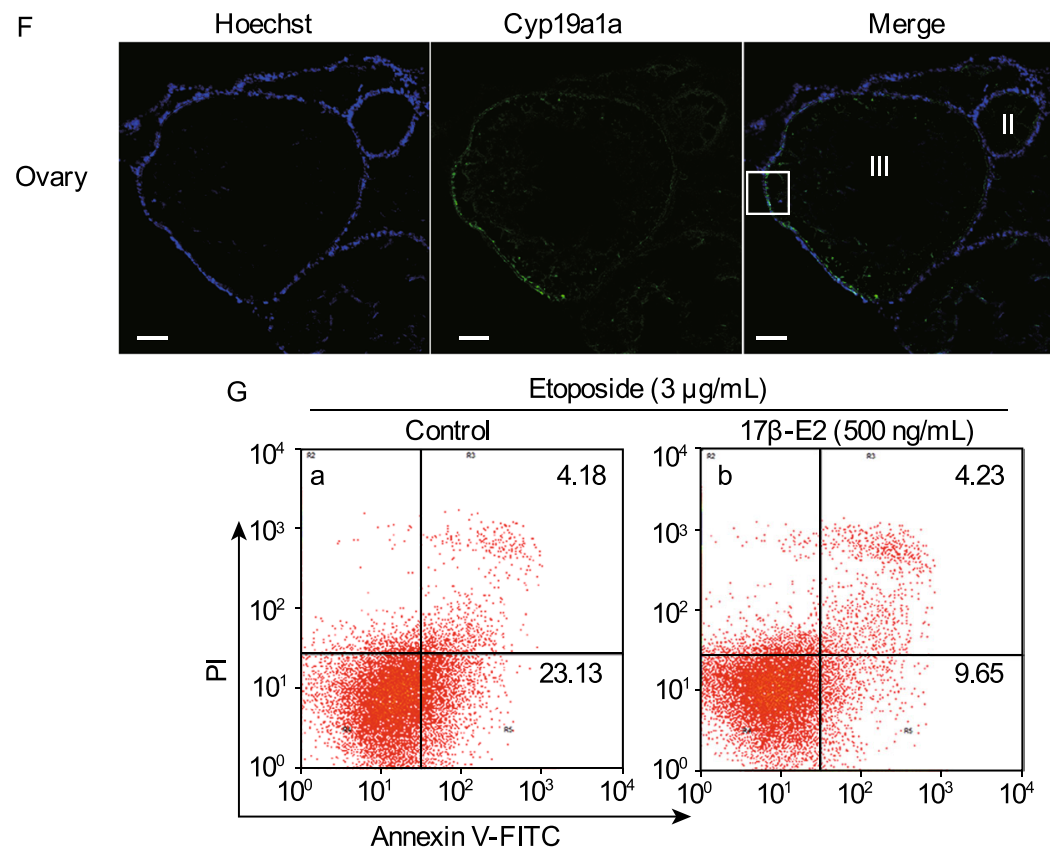

Enlarge

Control
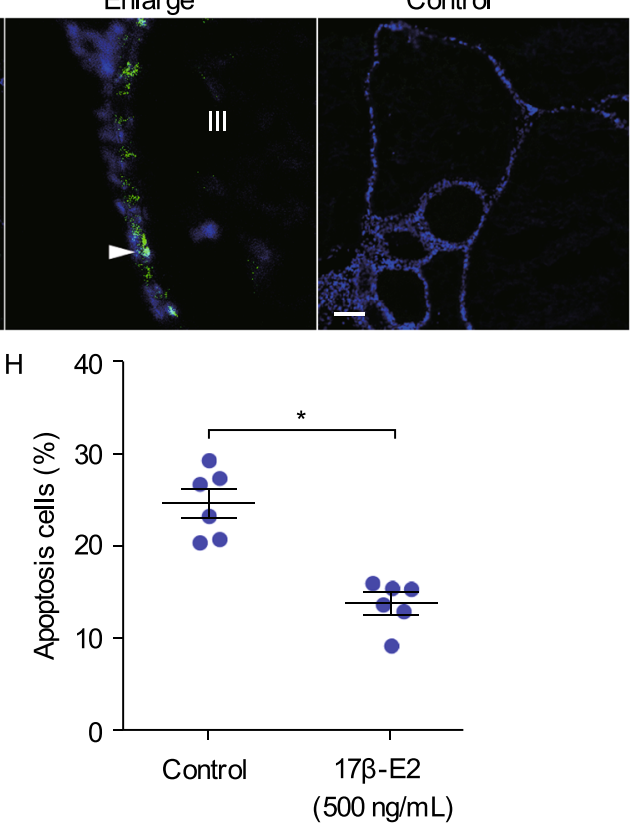
Figure 5. Disrupted pathway of $17 \beta-E 2$ synthesis and upregulated apoptosis in the sox $3^{-1-}$ ovaries. (A) The expression levels of cyp19a1a in both sox $^{+/+}$and sox $3^{-/-}$ovaries based on RNA-seq data. (B) Quantitative real-time PCR analysis of cyp19a1a expression levels in both $s o x 3^{+/+}$and sox $3^{-1-}$ ovaries. The transcript levels were related to $\beta$-actin expression. Relative level, $2^{-\Delta \Delta \mathrm{Ct}}$. T-test was performed. ${ }^{*} P<$ 0.05. (C) The standard curve of $17 \beta-E 2$ concentration at $\mathrm{OD}_{450}$. (D) Down-regulated $17 \beta-\mathrm{E} 2$ in sox $3^{-/-}$gonads in comparison with the wild type gonads. Data represented means \pm SEM. T-test was performed. ${ }^{*} P<0.05$; ${ }^{\star *} P<0.01$. (E) Immunofluorescence analysis of Sox 3 protein in adult ovary. Anti-Sox 3 and FITC-conjugated goat anti-rabbit $\lg G(\mathrm{H}+\mathrm{L})$ antibodies were used to detect Sox3 (green). The nuclei were stained by Hoechst (blue). Preimmune serum was used as a negative control. The white square area in the inset was enlarged and showed on the right. Sox3 positive signals were observed in somatic cells (theca cells and granulosa cells) (white arrowheads) in ovary. Scale bar, $50 \mu \mathrm{m}$. (F) Immunofluorescence analysis of Cyp19a1a protein in adult ovary. Anti-Cyp19a1a and FITC-conjugated goat anti-rabbit $\lg G(H+L)$ antibodies were used to detect Cyp19a1a (green). The nuclei were stained by Hoechst (blue). Preimmune serum was used as a negative control. The white square area in the inset was enlarged and showed on the right. Cyp19a1a positive signals were observed in somatic cells (theca cells and granulosa cells) (white arrowheads) in ovary. Scale bar, $50 \mu \mathrm{m}$. (G) Assessment of apoptosis using Annexin V-FITC/PI and flow cytometry. CHO cells were treated with $17 \beta-E 2(500 \mathrm{ng} / \mathrm{mL})$ or DMEM (control) for $36 \mathrm{~h}$, and then treated with etoposide $(3 \mu \mathrm{g} / \mathrm{mL})$ for $12 \mathrm{~h}$ and assayed by flow cytometry. Viable cells exhibited Annexin V-/PI(symbol 3 in the plot); early apoptotic cells exhibited Annexin $V$ $+/ \mathrm{PI}$-(symbol 4 in the plot); late apoptotic cells exhibited Annexin $\mathrm{V}+\mathrm{PI}+$ (symbol 1 in the plot); necrotic cells and some late apoptotic cells exhibited Annexin V-/PI+ (symbol 2 in the plot). (H) Percentages of both early and late apoptotic cells based on the apoptosis assessment by flow cytometry and Annexin V/PI in (G). T-test was performed. ${ }^{*} P<0.05$.

To investigate how depletion of sox3 influences ovary apoptosis, we analyzed pathways of Cyp19a1a regulation. Because Cyp19a1a can promote 17ß-E2 synthesis (Miller, 2017), we examined possible association of cyp19a1a expression with $17 \beta-E 2$ production in ovary. Synthesis level of $17 \beta-E 2$ were indeed decreased in ovaries, while expression level of cyp19a1a in ovaries were significantly downregulated in two knockout lines in comparison with wild type (Fig. 5A-D). Immunofluorescence analysis further showed that both Sox3 and Cyp19a1a proteins had a similar expression pattern in somatic cells (theca cells and granulosa cells) in ovary (Fig. $5 \mathrm{E}$ and $5 \mathrm{~F}$ ). To further confirm regulation relationship between $17 \beta-E 2$ and apoptosis, we treated $\mathrm{CHO}$ cells with $17 \beta-\mathrm{E} 2$ and then added etoposide to test apoptosis level. Addition of $17 \beta-E 2$ significantly inhibited apoptosis level in etoposide-induced $\mathrm{CHO}$ cells (Fig. 5G and $5 \mathrm{H})$. These results suggested that Sox3 up-regulated cyp19a1a expression, which promoted 17ß-E2 synthesis, thus inhibited apoptosis in ovary development.

\section{Sox3 binds to and activates cyp19a1a promoter in zebrafish}

To examine the role of Sox3 in regulating cyp19a1a expression in zebrafish, a series of deletions of the cyp19a1a promoter were used to identify possible binding sites of Sox3. Three Sox 3 binding sites ( $a, b$ and $c$ ) were detected with a consensus motif according to JASPAR database (Fig. 6A and 6B). To identify the exact binding sites, luciferase activities in a series of deletions were examined. The results showed that the sequence from -257 to $-220 \mathrm{bp}$ in the $5^{\prime}$ flanking region was key for cyp19a1a transcriptional activity, which harbored two Sox3 binding sites (b and c) (Fig. 6A and 6B). To identify the roles of these sites, site-directed mutants were constructed using wild-type pGL3-cyp19a1a-2 plasmid as the template. Compared with the wild-type pGL3-cyp19a1a-2 construct, a single mutant showed an obvious decrease in promoter activity, and the activity was obviously deprived in double mutants (Fig. 6C and 6D). Furthermore, Sox3 transfection can up-regulate the pGL3-cyp19a1a-2-driven luciferase activity, whereas Sox3 had no effect on the promoter activities of the single or double sites mutation-driven luciferase activity, suggesting that Sox3 can bind to both sites in the cyp19a1a promoter and activate the promoter activity (Fig. 6E). Chromatin immunoprecipitation analysis was further performed to investigate whether Sox3 binds to the cyp19a1a promoter in vivo. A 382 bp DNA region from anti-Sox3 antibody precipitates was amplified in ovary, which was confirmed by sequencing. Another distinct genomic region (exon 4) was used as a control to exclude the possibility of nonspecific binding to the cyp19a1a promoter region. In the control, no band from the anti-Sox3 antibody precipitates was observed (Fig. 6F and 6G). These results suggested that Sox3 can bind to both sites (b and c) in the cyp19a1a promoter and activate the promoter activity in the zebrafish ovary.

\section{DISCUSSION}

Folliculogenesis is an important event for production of functional eggs in vertebrates, which could rely on the balance between pro-apoptosis and anti-apoptosis. However, the regulatory mechanisms underlying folliculogenesis via apoptosis remain elusive. In the present study, we provided a molecular mechanism of apoptosis-regulated follicle development in zebrafish. We revealed the Sox3 as a regulator of Cyp19a1a expression, which can inhibit ovarian apoptosis via $17 \beta-E 2$ to ensure dominant follicle development. Sox3 knockout can disrupt the regulatory pathway, 
4

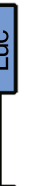

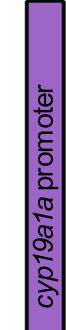

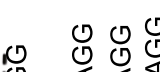

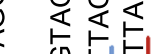

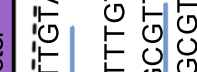

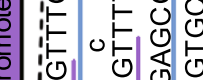

竞

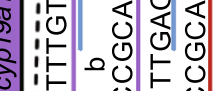

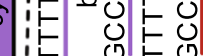

i.

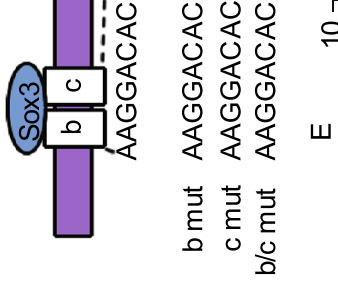

[ [ t $1,1,1,1+$

u

9

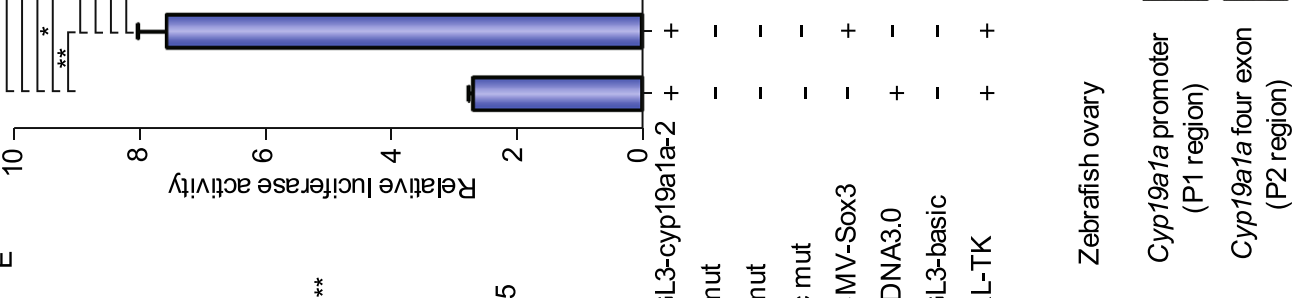

$1+1+10+10$

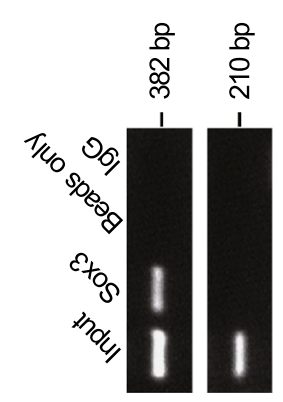

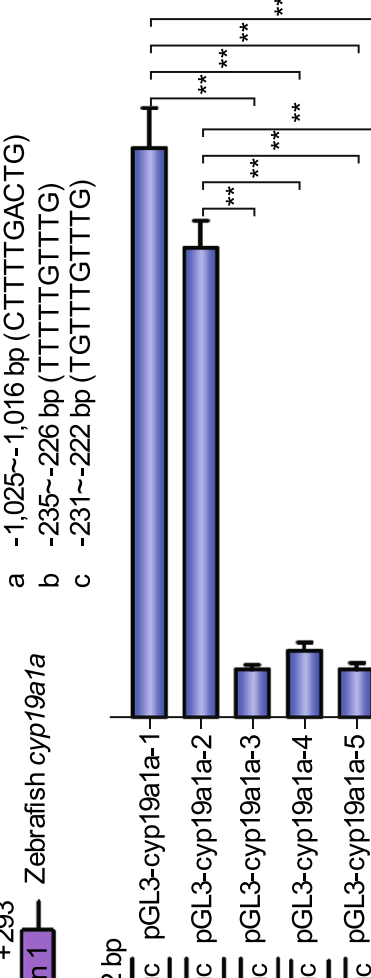

+

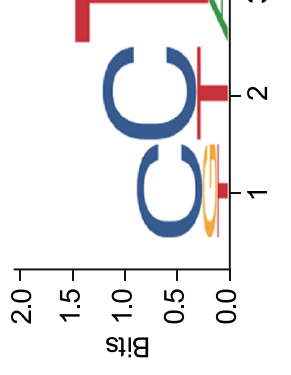

$\varangle$

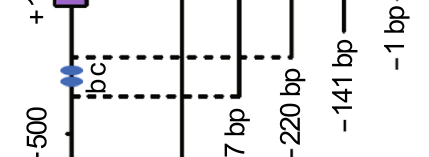

[م 
Figure 6. Activity analysis of cyp19a1a promoter. (A) Sequence logo of Sox3 binding site based on JASPAR database. (B) Luciferase assay showed the activities of a series of deleted constructs in HEK293T cells, which corresponded to three sox3 binding sites ( $a, b$ and $c$ ). Left panel showed each deleted mutant linked with the luciferase gene in the pGL3-basic vector. Right panel indicated the relative activities of these deleted constructs, as determined by luciferase assays. One-way ANOVA was performed. ${ }^{*} P<0.05$; ${ }^{* *} P<0.01$. (C) The DNA sequences of mutants (b, $c$ and b/c) and wild type cyp19a1a. (D) Point mutation analysis of the core promoter using luciferase assays. The 329 bp pGL3-cyp19a1a-2 construct was used as a basic construct for the point mutation analysis. Luciferase assays were used to determine the relative activities. The intact binding sites of the Sox 3 were indicated by open boxes, respectively. The filled boxes showed corresponding mutation. The pGL3-basic vector was used as a negative control. The data were based on the luciferase activity of pGL3cyp19a1a-2. The means \pm SD are from 3 independent experiments. One-way ANOVA was performed. ${ }^{*} P<0.05$; ${ }^{* *} P<0.01$. (E) Overexpression of Sox3 up-regulated cyp19a1a promoter activity. HEK293T cells were transfected with $0.32 \mu \mathrm{g}$ pGL3cyp19a1a-2 or its several mutants (b, c and b/c) and $0.08 \mu \mathrm{g}$ Sox3 expression plasmid (pCMV-Sox3), together with $10 \mathrm{ng}$ pRL-TK, as indicated. One-way ANOVA was performed. ${ }^{*} P<$ $0.05 ;{ }^{*} P<0.01$. (F) Schematic diagram of primer relative positions in the ChIP assay. (G) Chromatin immunoprecipitation analysis showed that Sox3 can bind to the cyp19a1a promoter in vivo. Sonicated chromatin from zebrafish ovaries were immunoprecipitated with anti-Sox3, no antibody (beads only) and preimmune lgG (control). A $382 \mathrm{bp}$ fragment corresponding to the -493 to -112 region of the cyp19a1a promoter was amplified using the immunoprecipitated DNA as a template. Exon 4 of cyp19a1a was used as a negative control.

lead to apoptosis of granulosa cells and theca cells in ovary, thus retardation of follicle development and a reduced fecundity in females. These findings have potential implications in improving female fecundity through the apoptosis suppression pathway.

We have demonstrated that sox 3 is required for follicle development and fecundity in zebrafish. Excess follicular atresia and severely reduced fertility in the sox $3 \mathrm{KO}$ mice were observed (Weiss et al., 2003; Rizzoti et al., 2004), which might be caused by apoptosis. Here, we determined the molecular connection between apoptosis and follicle development retardation by the Sox3-Cyp19a1a. In addition to gonad development, Sox3 was associated with X-linked mental retardation, growth hormone deficiency and X-linked panhypopituitarism in humans (Laumonnier et al., 2002; Bauters et al., 2014; Jelsig et al., 2018), and was required for the functions of pituitary and formation of midline structures in central nervous system in mice (Rizzoti et al., 2004). Knockdown of Sox3 resulted in a reduction in the size of the CNS, ears and eyes and inhibition of neurogenesis (Dee et al., 2008), while both Sox3 and Sox2 regulated otic/epibranchial placode induction and inner ear development in zebrafish (Gou et al., 2018a; Gou et al., 2018b). Besides, a decreased viability phenotype in the sox3 knockout zebrafish was observed in our study, which is similar to that in the sox3 knockout mice ( $43 \%$ death before weaning) (Rizzoti et al., 2004). Thus, Sox3 has dual functions in development of both gonad and brain.

Sox3, as a member of SOXB1 family, had a DNA-binding domain and a transactivation domain. The transactivation domain is essential for transcriptional activation of sox3, while the DNA-binding domain is for targeting of its downstream genes. Both sox $3^{f 7}$ and sox $3^{f 40}$ mutants had loss of function of Sox3 in zebrafish, as deletion of transactivation domain. Deletions of either of these two domains led to the loss-of-function of sox 3 for oncogenic transformation in chicken embryo fibroblasts (Xia et al., 2000). Similarly, the full-length of sox3 could rescue the morphological defect caused by the knockdown of sox $2 / 3 / 19 a / 19 b$, whereas loss of the transactivation domain led to loss-of-function of Sox3 in zebrafish embryos (Okuda et al., 2010). In the present study, we observed that the truncated Sox $3^{\mathrm{f7}}$ and Sox $3^{\mathrm{f} 40}$ without the transactivation domain probably have no dominant negative roles to occupy competitively DNA binding sites for other Sox family proteins, owe to transcript destabilization and degradation in $\operatorname{sox} 3^{f 7}$ and $\operatorname{sox} 3^{f 40}$ mutants. A similar knockout strategy was also used in irf6 ( $\mathrm{Li}$ et al., 2017) and hemogen (Peters et al., 2018) knockout zebrafish, which showed transcripts destabilization and degradation of truncated Irf6 and Hemogen by NMD, and significantly decreased protein production. Therefore, if a few truncated transcripts were translated, the proteins might have been rapidly degraded (Chen et al., 2016; Facchinello et al., 2017). However, it cannot exclude a weak dominant-negative effect on other target genes, as Sox18 missing part of the transactivation domain may act in a dominant-negative manner (Pennisi et al., 2000a; Pennisi et al., 2000b).

Importantly, we revealed that Sox 3 acts as an apoptosis suppressor in ovary development. Transcriptome analysis showed that the apoptosis signaling pathway was significantly up-regulated in sox $3^{-1-}$ ovaries in comparison with wild type ovaries. Specifically, Cleaved-caspase3 was upregulated in sox3 knockout ovaries compared to wild type ovaries. Notably, obvious apoptosis signals were detected in both theca cells and granulosa cells of stages III and IV follicles of sox $3^{-1-}$ ovaries. Thus, Sox3 can suppress apoptosis of somatic theca cells and granulosa cells in ovary. Because of the apoptosis, reduced nutrients from the somatic cells for oocyte development lead to follicle development retardation, thus fecundity decrease. Apoptosis was also up-regulated in early stage of embryo in sox3 knockdown zebrafish (Dee et al., 2008) and overexpression of Sox3 inhibited apoptosis in epithelial ovarian cancer cell (Yan et al., 2016). In women, a high percentage of apoptosis in granulosa cells resulted in decreased ovarian fecundity 


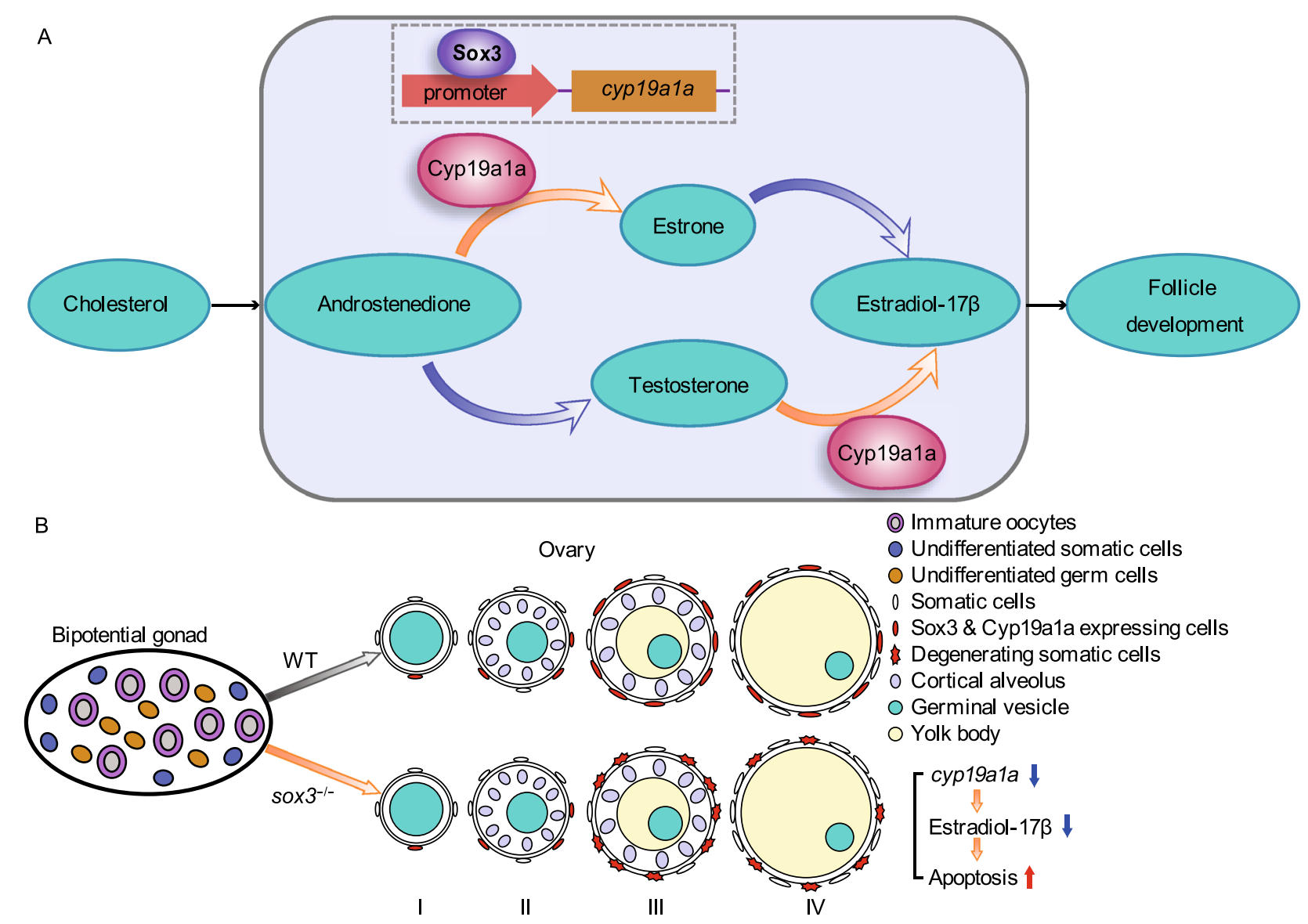

Figure 7. A work model for Sox3-Cyp19a1a in ovary development in zebrafish. (A) The pathway of 17ß-E2 synthesis in ovary. Sox 3 binds to the promoter of cyp19a1a and up-regulates the cyp19a1a expression, which promotes $17 \beta$-E2 synthesis via the two pathways, one is that androstenedione is converted to estrone and another is that testosterone is converted to 17 $\beta$-E2. (B) Wild-type juvenile gonads are bipotential between 22-28 dpf post fertilization. Cyp19a1a promotes ovary development by up-regulation of $17 \beta-$ E2 synthesis in wild type. In the absence of Sox3, the expression level of cyp19a1a is down-regulated, which results in a decrease of $17 \beta-E 2$, thus leads to somatic cell apoptosis in follicles, mostly at early-vitellogenic stage (III) and late-vitellogenic stage (IV), and a reduced fecundity.

(Sadraie et al., 2000) and pregnancy rate (Sifer et al., 2002). Hence, up-regulation of apoptosis of somatic cells can affect ovary function. In addition, balance between pro-apoptosis and anti-apoptosis is important for pathological and physiological processes. As a suppressor, Sox 3 can balance the apoptotic level in ovary development, thus ensure normal fecundity in females.

Sox3 functions as a regulator of Cyp19a1a expression, via $17 \beta-E 2$ linking apoptosis suppression, which is implicated in improving female fecundity. Sox 3 can bind to the promoter of cyp19a1a and up-regulate Cyp19a1a expression in zebrafish ovary. The similar Sox3 binding site at intron 1 and activation of ovary-type cyp19a gene were also observed in frog (Rana rugosa) (Oshima et al., 2009). As a cytochrome P450 aromatase, Cyp19a1a can promote estrogen synthesis via two pathways, conversion of androstenedione to estrone, and conversion of testosterone to 17ß-E2 (Nagahama, 1997). Knockout of cyp19a1a led to all-male offspring due to failed ovarian differentiation and the phenotype can be rescued by $17 \beta-E 2$ treatment, indicating that Cyp19a1a-17ß-E2 were necessary for female follicle development (Dranow et al., 2016; Lau et al., 2016; Yin et al., 2017). Thus, we determined Sox3 as the upstream regulator of Cyp19a1a-17ß-E2 in ovary function. Juvenile gonads of zebrafish are bipotential between 22-28 dpf post fertilization. Cyp19a1a promotes ovary development by upregulation of $17 \beta-E 2$ synthesis in wild type. In the absence of sox3, the expression level of cyp19a1a is down-regulated, which results in a decrease of $17 \beta-E 2$, thus leads to somatic cell apoptosis in follicles, mostly at early-vitellogenic stage (III) and late-vitellogenic stage (IV), and a reduced fecundity (Fig. 7A and 7B). 17ß-E2 can inhibit apoptosis of granulosa cells and theca cells, probably by Fas ligand (FasL)-induced pathway (Quirk et al., 2006; Regan et al., 2018). In addition, 
$17 \beta-E 2$ can also promote DNA synthesis in ovarian germ cells and act direct on oogonial proliferation (Miura et al., 2007). It seems that $17 \beta-E 2$ has distinct roles in different cell types in ovary development. Aromatase inhibitor (fadrozole) can also cause sex-reversal from genetic female larvae to phenotypic males in Japanese flounder (Kitano et al., 2000), Nile tilapia (Kobayashi et al., 2003) and zebrafish (Uchida et al., 2004), and exposure to $17 \beta$-E2 during embryo-larvaejuvenile-life stage led to an increase proportion of females in zebrafish (Brion et al., 2004). These data support that 17ßE2 can promote ovary differentiation. In addition, FTZ-F1/ SF-1 in medaka (Oryzias latipes) (Watanabe et al., 1999) and bovine (Michael et al., 1995), and Foxl2 in Nile tilapia (Oreochromis niloticus) (Wang et al., 2007a) and goat (Pannetier et al., 2006) can also up-regulate the transcription of ovary-type cyp19a1, whereas Dmrt1 can suppress cyp19a1a expression in Nile tilapia (Wang et al., 2010). Further, ovary- or brain-specific transcription factors of cyp19a1a/cyp19a1b genes remain to be identified.

\section{MATERIALS AND METHODS}

\section{Zebrafish maintenance}

Wild-type $A B$ strain zebrafish (Danio rerio) were purchased from Institute of Hydrobiology of Chinese Academy of Sciences (Wuhan, China). Zebrafish strains were maintained and raised in recirculation systems at $28.5^{\circ} \mathrm{C}$ under a cycle of $14 \mathrm{~h}: 10 \mathrm{~h}$ light/dark. All animal experiments and methods were performed in accordance with the relevant approved guidelines and regulations, as well as under the approval of the Ethics Committee of Wuhan University.

\section{Generation of sox3 mutant lines and genotyping}

The pGH-T7-zCas9 plasmid was linearized by Xbal and used as a template for in vitro transcription using the mMessage mMachine T7 Ultra Kit (Ambion AM1345, Austin, TX, USA). Sox3 guide RNA (gRNA) was synthesized using a protocol according to previously described methods (Liu et al., 2014a). The oligonucleotides were synthesized by TsingKe Biotechnology (Wuhan, China) (Oligo-F: 5' TGTAATACGACTCACTATAGGTGTCGGTGGGCCAGCGGAGTTTT AGAGCTAGAAATAGC 3'; Oligo-R: 5' AGCACCGACTCGGTGCC ACT $3^{\prime}$ ). T7 promoter sequence was added to the $5^{\prime}$ - upstream of the oligo-F. PCR amplification using the primers and gRNA scaffold plasmid was performed to generate template for the sox3 gRNA synthesis. The gRNA was in vitro transcribed using the T7 RNA Polymerase Systems (Thermo Fisher Scientific, Grand Island, NY, USA). The transcribed Cas9 mRNA and gRNA were further purified by RNeasy Mini Kit (Qiagen 74104, Germany). Embryos were collected by pair mating, maintained in Hank's medium. Cas 9 mRNA (300 ng/ $/ \mathrm{L})$ and gRNA (20 ng/ $\mathrm{LL}$ ) were mixed and microinjected into wild-type embryos at one-cell stage using a microinjector (PV820, WPI, USA). Injected embryos were collected after $48 \mathrm{~h}$ for isolation of genomic DNA using $\mathrm{NaOH}$-based extraction method. The target region was amplified by PCR and indel mutations were verified by sequencing. To identify germline-transmitted mutations, the injected founder embryos $\left(F_{0}\right)$ were raised to adulthood and then crossed with wild-types to generate heterozygous embryos $\left(F_{1}\right)$. Genotyping was performed by PCR amplification of target sites using caudal fin DNA and sequencing. The same indel mutants of $F_{1}$ were intercrossed to generate homozygous embryos $\left(\mathrm{F}_{2}\right)$. Two independent sox3 mutant lines were established.

\section{Antibodies}

Primary antibodies: Anti-Sox3 (GeneTex, GTX132494) was purchased from GeneTex, Irvine, California, USA. Anti-caspase3 $(\mathrm{H}$ 277) was from ZSGB-BIO, Beijing, China. Anti-Gapdh (glyceraldehyde-3-phosphate dehydrogenase, CW0100) was purchased from CWBIO, Beijing, China. Anti-Cyp19a1 (A12684) was from ABclonal, Wuhan, China.

Secondary antibodies: goat anti-rabbit $\lg G(H+L)$, horseradish peroxidase (HRP) conjugated antibody (31460) and goat anti-mouse $\lg G(H+L)$, HRP conjugated antibody (31430) were purchased from Invitrogen, Carlsbad, USA. FITC-conjugated immunopure goat antirabbit $\lg G(H+L)(Z F-0311)$ was from Feiyi Technology, Wuhan, China.

\section{Plasmid constructs}

Full-length sox3 (NM_001001811.2) was cloned into pcDNA3.0 using EcoRI and Xhol to generate pCMV-Sox3. Five deletion fragments of the zebrafish cyp19a1a promoter were amplified from zebrafish genomic DNA, which were double-digested with Sacl and Bg/ll and cloned into the pGL3-basic vector (E1751, Promega, Madison, WI, USA). The primers and PCR conditions are described in Table S1. Site-directed mutagenesis for the two Sox3 binding sites (b and $c$ ) were performed using the primers described in Table S1. cyp19a1a $\left(b^{\text {mut }}\right)$ was used as the template for constructing both cyp19a1a $\left(b^{\text {mut }}\right)$ and cyp19a1a $\left(\mathrm{c}^{\mathrm{mut}}\right)$ mutants. All constructs were sequenced.

\section{RNA isolation and quantitative real-time PCR}

Total RNAs of zebrafish tissues were isolated using the TRIzol Reagent (15596-026, Thermo Fisher) and then were treated with RNase-free DNase (M610A, Promega, Madison, WI, USA). The total RNAs were reverse-transcribed to complementary DNAs (cDNAs) using MMLV (M1701, Promega). SYBR Green qPCR Mix (D01010, GeneCopoeia, Rockville, MD, USA) was used for quantitative real-time PCR amplification in a StepOne real-time PCR system (Applied Biosystems, USA). The primers and PCR conditions are listed in Table S1.

\section{Immunofluorescence analysis}

Immunofluorescence analysis was performed according to our previous study (Hou et al., 2012). Zebrafish ovaries were embedded into OCT medium (4583, Sakura Tissue-Tek, Torrance, CA, USA) and frozen at $-20^{\circ} \mathrm{C}$, and then cut into a series of $6 \sim 7 \mu \mathrm{m}$ sections using a cryostat (CM1850, Leica, Bensheim, Germany). The sections were fixed with $4 \%$ paraformaldehyde (PFA) for 20 min at room temperature and permeabilized with $1 \%$ Triton $\mathrm{X}-100$ (9002-93-1, Sigma-Aldrich, USA) in PBS for $10 \mathrm{~min}$ and then blocked in $5 \%$ bovine serum albumin (BSA)/PBS for $30 \mathrm{~min}$ at room temperature. The sections were incubated with anti-Sox3 or anti-Cyp19a1 polyclonal antibody in $5 \%$ BSA/PBS overnight at $4{ }^{\circ} \mathrm{C}$. 
After washing 3 times with PBS, the sections were incubated with FITC-conjugated immunopure goat anti-rabbit $\operatorname{lgG}$ for $1 \mathrm{~h}$ at room temperature. The nuclei were stained by Hoechst. Images were captured by a confocal fluorescence microscope (FV1000, Olympus, Tokyo, Japan).

\section{Western blot analysis}

Western blots were performed according to our previous protocols (Yuan et al., 2015). Protein extracts from zebrafish ovaries were separated in $12 \%$ SDS-polyacrylamide gels and then transferred onto $0.45 \mu \mathrm{m}$ PVDF membranes (NK0414, Roche Diagnostics, Indianapolis, IN, USA). The membranes were then blocked with $5 \%$ non-fat dried milk in TBST $(20 \mathrm{mmol} / \mathrm{L}$ Tris- $\mathrm{HCl}, \mathrm{pH} 7.5,150 \mathrm{mmol} / \mathrm{L}$ $\mathrm{NaCl}, 0.1 \%$ Tween-20) for $1 \mathrm{~h}$ at room temperature. The primary antibodies were incubated with the membranes overnight at $4{ }^{\circ} \mathrm{C}$. The membranes were washed in TBST 4-5 times, incubated with the HRP-conjugated secondary antibody for $1 \mathrm{~h}$ at room temperature and then washed in TBST 4-5 times. A super signal chemiluminescent substrate system (K-12045-D50, advansta, Menlo Park, USA) was used to detect the signals.

\section{Cell culture, transfection and dual-luciferase reporter assays}

HEK293T and CHO cells were cultured in high glucose Dulbecco's modified Eagle's medium (DMEM) (SH30022.01B, HyClone, Logan, USA) with $10 \%$ fetal bovine serum (FBS) (P30-330250, PAN-Biotech, Aidenbach, Germany) in 12/48-well plates and Lipofectamine $^{\mathrm{TM}} 2000$ (11668027, Invitrogen) was used for transfection according to the routine protocol. For luciferase assays, cells per well was transfected with $0.4 \mu \mathrm{g}$ recombinant constructs and $10 \mathrm{ng}$ pRL-TK (E2241, Promega). Then luciferase activities were measured by a dual-luciferase reporter assay system (Promega, Madison, WI, USA) and a Modulus Single Tube Multimode Reader (Turner Biosystems, Sunnyvale, CA, USA) according to the manufacturer's protocol. The experiments were repeated at least 3 times, and the results were expressed as the means $\pm S D$.

\section{Chromatin immunoprecipitation (ChIP)}

Chromatin immunoprecipitation was performed according to our previous study (Fu et al., 2015). Zebrafish ovaries were cut into small pieces in PBS and a final concentration of $1 \%$ formaldehydePBS was used for crosslinking for $20 \mathrm{~min}$ at room temperature. Glycine was added to terminate crosslinking in a final concentration of $0.125 \mathrm{~mol} / \mathrm{L}$. Then the supernatant chromatin was immunoprecipitated with anti-Sox3, no antibody (beads only) or preimmune IgG together with protein G PLUS-agarose (Sc-2002, Santa Cruz, USA). The DNA isolated from the immunoprecipitated complex was amplified by PCR using primers flanking the Sox3 binding region ( -493 to $-112 \mathrm{bp})$ and control region $(7,708$ to $7,917 \mathrm{bp}$ ) (Table S1). The PCR products were cloned into T-easy vector (A137A, Promega, Madison, USA) and sequenced.

\section{Histological and TUNEL assays}

Zebrafish ovaries were embedded into OCT medium (4583, Sakura Tissue-Tek) and frozen at $-20{ }^{\circ} \mathrm{C}$, and then cut into a series of $6-7$ $\mu \mathrm{m}$ sections with a cryostat (CM1850, Leica). The sections were stained by haematoxylin and eosin (H.E.), and images were captured using a Leica microsystems (Leica). For TUNEL (terminal deoxynucleotidyl transferase-mediated dUTP-biotin nick end labeling) assays, TUNEL Apoptosis Assay Kit-FITC (AT005, Qihaifutai, Shanghai, China) was used according to the manufacturer's protocol. The sections were fixed with $4 \%$ paraformaldehyde for $20 \mathrm{~min}$ at room temperature and permeabilized with $20 \mu \mathrm{g} / \mathrm{mL}$ proteinase $\mathrm{K}$ (P2308, Sigma-Aldrich) for $10 \mathrm{~min}$ at room temperature, and then the sections were incubated with the TdT mix containing FITC-dUTP for $1 \mathrm{~h}$ at $37^{\circ} \mathrm{C}$. The nuclei were stained by propidium iodide $(\mathrm{PI})$ for 2 min. Images were captured by a confocal fluorescence microscope (FV1000, Olympus).

\section{Flow cytometry}

For apoptosis assays, Annexin V-FITC/PI Apoptosis Kit (WLA001, Wanleibio, Shenyang, China) was used according to the manufacturer's protocol. CHO cells were treated with $17 \beta-E 2(500 \mathrm{ng} / \mathrm{mL}$, E2758, Sigma-Aldrich) or DMEM (control) for $36 \mathrm{~h}$, and then treated with etoposide $(3 \mu \mathrm{g} / \mathrm{mL})$ for $12 \mathrm{~h}$ and assayed by flow cytometry (CyAn ADP, Beckman Coulter, Brea, USA). The data were analyzed according to Summit 4.3 Software (Beckman Coulter).

\section{Enzyme-linked immunosorbent assay (ELISA)}

Zebrafish ovaries and testes were cut into small pieces in cold PBS and sonication was performed using a sonicator (Sonics \& Materials Inc., Newtown, USA). The homogenates were centrifuged at $3000 \times g$ for $15 \mathrm{~min}$ and the supernatant was used to test $17 \beta$ estradiol according to the manufacturer's protocol (17 $\beta$-E2 ELISA Kit, mI0386133, MLBIO, Shanghai, China). Concentration of $17 \beta-E 2$ was determined based on standard curve of $17 \beta-E 2(0,87.5,175$, $350,700,1,400 \mathrm{pg} / \mathrm{mL}$ ) at $\mathrm{OD}_{450}$. The optical density (OD) was read at $450 \mathrm{~nm}$ using a microplate reader (SpectraMax M2, Molecular Devices, USA). Data (means \pm SEM) was analyzed by T-test.

\section{Transcriptome sequencing and analysis}

Total RNAs of ovaries were extracted from each genotype (sox $3^{+/+}$ or sox $3^{-/-}$) of three adult individuals. The mRNA was enriched using Oligo (dT) and then broken up for cDNA library construct according to the manufacturer's protocol. Then the cDNA library was sequenced using BGISEQ-500 platform. To determine gene expression levels, RNA-seq clean reads from sox $3^{+/+}$or sox $3^{-/-}$ ovaries were mapped to the reference genome by HISAT (Kim et al., 2015) and mapped to the reference genes by Bowtie2 (Langmead et al., 2009). Fragments per kilo bases per million fragments (FPKM) values were calculated for each gene by RSEM (Li and Dewey, 2011). Differentially expressed genes (DEGs) were defined with fold change $(F C)>1.4$ and false discovery rate $(F D R)<0.05$. The Gene Ontology (GO) of the DEGs was analyzed by the WEGO online tool (Ye et al., 2006). For the Kyoto Encyclopedia of Genes and Genomes (KEGG) analysis, the DEGs were implemented to map KEGG public database according to a previous study (Kanehisa et al., 2008). 


\section{Statistical analysis}

All data were presented as means \pm standard error of mean from at least three independent experiments. Statistical comparisons were made using Student's $t$-test when comparing two groups. One-way ANOVA was performed for comparisons with more than two groups. Statistics analysis was performed using GraphPad Prism 6 software package (GraphPad Software, La Jolla, USA). In all analysis, $P<$ 0.05 was considered to be statistically significant.

Data availability

Strains are available upon request. Transcriptome data were deposited in the GEO database (accession no. GSE115806). Supplemental information including materials and methods, four figures and four tables can be found in supplementary file. All primers used in this study are listed in Table S1.

\section{ACKNOWLEDGEMENTS}

We thank Dr. Zongbin Cui of Institute of Hydrobiology of Chinese Academy of Sciences for providing pGH-T7-zCas9 and gRNA scaffold plasmids. This work was supported by the National Natural Science Foundation of China and National Key Technologies R\&D Program.

\section{ABBREVIATIONS}

Amh, anti-Mullerian hormone; $\mathrm{Ar}$, androgen receptor; $\mathrm{Bax}, \mathrm{Bcl} 2$ associated X, apoptosis regulator; Bcl2, B-cell leukemia/lymphoma 2; Bmp15, bone morphogenic protein 15; Bok, Bcl2 family apoptosis regulator; Casp3a, caspase 3 , apoptosis-related cysteine peptidase a; ChIP, chromatin immunoprecipitation; CRISPR, clustered regularly interspaced short palindromic repeats; Cyp19a1a, cytochrome P450, family 19 , subfamily $A$, polypeptide $1 \mathrm{a}$; DEGs, differentially expressed genes; Dmrt1, doublesex and mab-3 related transcription factor 1; ELISA, enzyme-linked immunosorbent assay; FC, fold change; FDR, false discovery rate; Fgf24, fibroblast growth factor 24; FITC, fluorescein isothiocyanate; Foxl2a, forkhead box L2a; Foxl2b, forkhead box L2b; FPKM, fragments per kilo bases per million fragments; Gapdh, glyceraldehyde-3-phosphate dehydrogenase; Gdf9, growth differentiation factor 9; GEO, Gene Expression Omnibus; GO, Gene Ontology; gRNA, guide RNA; H.E., haematoxylin and eosin; KEGG, Kyoto encyclopedia of Genes and Genomes; Mcl1, myeloid cell leukemia sequence $1, \mathrm{Bcl} 2$ family apoptosis regulator; Mettl3, methyltransferase like 3; NrOb1, nuclear receptor subfamily 0 , group $\mathrm{B}$, member 1; OCT, optimal cutting temperature; $\mathrm{PI}$, propidium iodide; Pmaip1, phorbol-12-myristate-13-acetate-induced protein 1; QPCR, quantitative real-time PCR; Sox3, sex determining region Y-box3; Sox9a, sex-determining region $Y$-box $9 a$; Sry, sex determining region Y; Tspo, translocator protein; TUNEL, TdT-mediated dUTP nick end labeling; $17 \beta-E 2,17 \beta$-estradiol.

\section{COMPLIANCE WITH ETHICS GUIDELINES}

Qiang Hong, Cong Li, Ruhong Ying, Heming Lin, Jingqiu Li, Yu Zhao, Hanhua Cheng and Rongjia Zhou declare that they have no conflict of interest. All institutional and national guidelines for the care and use of laboratory animals were followed.

\section{AUTHOR CONTRIBUTIONS}

R. Zhou and H. Cheng conceived and designed research; Q. Hong, C. Li, R. Ying, H. Lin, J. Li and Y. Zhao carried out the experimental work; Q. Hong and R. Zhou analyzed data and wrote the manuscript. All authors read and approved the final manuscript.

\section{OPEN ACCESS}

This article is distributed under the terms of the Creative Commons Attribution 4.0 International License (http://creativecommons.org/ licenses/by/4.0/), which permits unrestricted use, distribution, and reproduction in any medium, provided you give appropriate credit to the original author(s) and the source, provide a link to the Creative Commons license, and indicate if changes were made.

\section{REFERENCES}

Baker KE, Parker R (2004) Nonsense-mediated mRNA decay: terminating erroneous gene expression. Curr Opin Cell Biol 16:293-299

Bauters M, Frints SG, Van Esch H, Spruijt L, Baldewijns MM, de DieSmulders CEM, Fryns JP, Marynen P, Froyen G (2014) Evidence for increased SOX3 dosage as a risk factor for X-linked hypopituitarism and neural tube defects. Am J Med Genet Part A 164:1947-1952

Brion F, Tyler CR, Palazzi X, Laillet B, Porcher JM, Garric J, Flammarion $P$ (2004) Impacts of 17beta-estradiol, including environmentally relevant concentrations, on reproduction after exposure during embryo-larval-, juvenile- and adult-life stages in zebrafish (Danio rerio). Aquat Toxicol 68:193-217

Bylund M, Andersson E, Novitch BG, Muhr J (2003) Vertebrate neurogenesis is counteracted by Sox1-3 activity. Nat Neurosci 6:1162-1168

Chen S, Zhang H, Wang F, Zhang W, Peng G (2016) nr0b1 (DAX1) mutation in zebrafish causes female-to-male sex reversal through abnormal gonadal proliferation and differentiation. Mol Cell Endocrinol 433:105-116

Crowder CM, Lassiter CS, Gorelick DA (2018) Nuclear androgen receptor regulates testes organization and oocyte maturation in zebrafish. Endocrinology 159:980-993

Dee CT, Hirst CS, Shih YH, Tripathi VB, Patient RK, Scotting PJ (2008) Sox3 regulates both neural fate and differentiation in the zebrafish ectoderm. Dev Biol 320:289-301

Dranow DB, Hu K, Bird AM, Lawry ST, Adams MT, Sanchez A, Amatruda JF, Draper BW (2016) Bmp15 is an oocyte-produced signal required for maintenance of the adult female sexual phenotype in zebrafish. PLoS Genet 12:e1006323

Eppig JJ (2001) Oocyte control of ovarian follicular development and function in mammals. Reproduction 122:829-838

Facchinello N, Skobo T, Meneghetti G, Colletti E, Dinarello A, Tiso N, Costa R, Gioacchini G, Carnevali O, Argenton F et al (2017) nr3c1 null mutant zebrafish are viable and reveal DNA-binding- 
independent activities of the glucocorticoid receptor. Sci Rep 7:4371

Foster JW, Graves JAM (1994) An Sry-related sequence on the marsupial X-chromosome - implications for the evolution of the mammalian testis determining gene. Proc Natl Acad Sci USA 91:1927-1931

Fu XZ, Cheng YB, Yuan J, Huang CH, Cheng HH, Zhou RJ (2015) Loss-of-function mutation in the X-linked TBX22 promoter disrupts an ETS-1 binding site and leads to cleft palate. Hum Genet 134:147-158

Gou Y, Guo J, Maulding K, Riley BB (2018a) Sox2 and Sox3 cooperate to regulate otic/epibranchial placode induction in zebrafish. Dev Biol 435:84-95

Gou Y, Vemaraju S, Sweet EM, Kwon HJ, Riley BB (2018b) Sox2 and Sox3 play unique roles in development of hair cells and neurons in the zebrafish inner ear. Dev Biol 435:73-83

Guo YQ, Cheng HH, Huang X, Gao S, Yu HS, Zhou RJ (2005) Gene structure, multiple alternative splicing, and expression in gonads of zebrafish Dmrt1. Biochem Bioph Res Co 330:950-957

Haines B, Hughes J, Corbett M, Shaw M, Innes J, Patel L, Gecz J, Clayton-Smith J, Thomas P (2015) Interchromosomal insertional translocation at Xq26.3 alters SOX3 expression in an individual with XX male sex reversal. J Clin Endocr Metab 100:E815-E820

Hou Y, Yuan J, Zhou X, Fu XZ, Cheng HH, Zhou RJ (2012) DNA demethylation and USF regulate the meiosis-specific expression of the mouse miwi. PLoS Genet 8:e1002716

Hsu SY, Lai RJ, Finegold M, Hsueh AJ (1996) Targeted overexpression of $\mathrm{Bcl}-2$ in ovaries of transgenic mice leads to decreased follicle apoptosis, enhanced folliculogenesis, and increased germ cell tumorigenesis. Endocrinology 137:48374843

Hutt KJ (2015) The role of BH3-only proteins in apoptosis within the ovary. Reproduction 149:R81-R89

Jelsig AM, Diness BR, Kreiborg S, Main KM, Larsen VA, Hove H (2018) A complex phenotype in a family with a pathogenic SOX3 missense variant. Eur J Med Genet 61:168-172

Jeng SR, Wu GC, Yueh WS, Kuo SF, Dufour S, Chang CF (2018) Gonadal development and expression of sex-specific genes during sex differentiation in the Japanese eel. Gen Comp Endocrinol 257:74-85

Jones RL, Pepling ME (2013) Role of the antiapoptotic proteins BCL2 and MCL1 in the neonatal mouse ovary. Biol Reprod 88:18

Kanehisa M, Araki M, Goto S, Hattori M, Hirakawa M, Itoh M, Katayama T, Kawashima S, Okuda S, Tokimatsu T et al (2008) KEGG for linking genomes to life and the environment. Nucleic Acids Res 36:D480-D484

Kim D, Landmead B, Salzberg SL (2015) HISAT: a fast spliced aligner with low memory requirements. Nat Methods 12:357-360

Kitano T, Takamune K, Nagahama Y, Abe SI (2000) Aromatase inhibitor and 17alpha-methyltestosterone cause sex-reversal from genetical females to phenotypic males and suppression of P450 aromatase gene expression in Japanese flounder (Paralichthys olivaceus). Mol Reprod Dev 56:1-5

Kobayashi T, Kajiura-Kobayashi H, Nagahama Y (2003) Induction of $\mathrm{XY}$ sex reversal by estrogen involves altered gene expression in a teleost, tilapia. Cytogenet Genome Res 101:289-294
Koopman P, Gubbay J, Vivian N, Goodfellow P, Lovell-Badge R (1991) Male development of chromosomally female mice transgenic for Sry. Nature 351:117-121

Langmead B, Trapnell C, Pop M, Salzberg SL (2009) Ultrafast and memory-efficient alignment of short DNA sequences to the human genome. Genome Biol 10:R25

Lau ESW, Zhang ZW, Qin MM, Ge W (2016) Knockout of zebrafish ovarian aromatase gene (cyp19a1a) by TALEN and CRISPR/ Cas9 leads to all-male offspring due to failed ovarian differentiation. Sci Rep 6:37357

Laumonnier F, Ronce N, Hamel BCJ, Thomas P, Lespinasse J, Raynaud M, Paringaux C, van Bokhoven H, Kalscheuer V, Fryns JP et al (2002) Transcription factor SOX3 is involved in X-linked mental retardation with growth hormone deficiency. Am J Hum Genet 71:1450-1455

Leerberg DM, Sano K, Draper BW (2017) Fibroblast growth factor signaling is required for early somatic gonad development in zebrafish. PLoS Genet 13:e1006993

Li B, Dewey CN (2011) RSEM: Accurate transcript quantification from RNA-Seq data with or without a reference genome. BMC Bioinform 12:323

Li EB, Truong D, Hallett SA, Mukherjee K, Schutte BC, Liao EC (2017) Rapid functional analysis of computationally complex rare human IRF6 gene variants using a novel zebrafish model. PLoS Genet 13:e1007009

Liew WC, Bartfai R, Lim Z, Sreenivasan R, Siegfried KR, Orban L (2012) Polygenic sex determination system in zebrafish. PLoS ONE 7:e34397

Lin Q, Mei J, Li Z, Zhang X, Zhou L, Gui JF (2017) Distinct and cooperative roles of amh and dmrt1 in self-renewal and differentiation of male germ cells in zebrafish. Genetics 207:1007-1022

Liu D, Wang Z, Xiao A, Zhang Y, Li W, Zu Y, Yao S, Lin S, Zhang B (2014a) Efficient gene targeting in zebrafish mediated by a zebrafish-codon-optimized Cas9 and evaluation of off-targeting effect. J Genet Genom 41:43-46

Liu J, Yao W, Yao Y, Du X, Zhou J, Ma B, Liu H, Li Q, Pan Z (2014b) MiR-92a inhibits porcine ovarian granulosa cell apoptosis by targeting Smad7 gene. FEBS Lett 588:4497-4503

Matsuda F, Inoue N, Manabe N, Ohkura S (2012) Follicular growth and atresia in mammalian ovaries: regulation by survival and death of granulosa cells. J Reprod Dev 58:44-50

Michael MD, Kilgore MW, Morohashi K, Simpson ER (1995) Ad4BP/ SF-1 regulates cyclic AMP-induced transcription from the proximal promoter (PII) of the human aromatase P450 (CYP19) gene in the ovary. J Biol Chem 270:13561-13566

Miller WL (2017) Steroidogenesis: unanswered questions. Trends Endocrinol Metab 28:771-793

Miura C, Higashino T, Miura T (2007) A progestin and an estrogen regulate early stages of oogenesis in fish. Biol Reprod 77:822-828

Moalem S, Babul-Hirji R, Stavropolous DJ, Wherrett D, Bagli DJ, Thomas P, Chitayat D (2012) XX male sex reversal with genital abnormalities associated with a de novo SOX3 gene duplication. Am J Med Genet Part A 158A:1759-1764

Nagahama $Y$ (1997) 17 alpha,20 beta-dihydroxy-4-pregnen-3-one, a maturation-inducing hormone in fish oocytes: mechanisms of synthesis and action. Steroids 62:190-196 
Okuda Y, Ogura E, Kondoh H, Kamachi Y (2010) B1 SOX coordinate cell specification with patterning and morphogenesis in the early zebrafish embryo. PLoS Genet 6:e1000936

Orban L, Sreenivasan R, Olsson PE (2009) Long and winding roads: testis differentiation in zebrafish. Mol Cell Endocrinol 312:35-41

Oshima Y, Naruse K, Nakamura Y, Nakamura M (2009) Sox3: a transcription factor for Cyp19 expression in the frog Rana rugosa. Gene 445:38-48

Pannetier M, Fabre S, Batista F, Kocer A, Renault L, Jolivet G, Mandon-Pepin B, Cotinot C, Veitia R, Pailhoux E (2006) FOXL2 activates $P 450$ aromatase gene transcription: towards a better characterization of the early steps of mammalian ovarian development. J Mol Endocrinol 36:399-413

Pennisi D, Bowles J, Nagy A, Muscat G, Koopman P (2000a) Mice null for sox18 are viable and display a mild coat defect. Mol Cell Biol 20:9331-9336

Pennisi D, Gardner J, Chambers D, Hosking B, Peters J, Muscat G, Abbott C, Koopman P (2000b) Mutations in Sox18 underlie cardiovascular and hair follicle defects in ragged mice. Nat Genet 24:434-437

Perez GI, Robles R, Knudson CM, Flaws JA, Korsmeyer SJ, Tilly JL (1999) Prolongation of ovarian lifespan into advanced chronological age by Bax-deficiency. Nat Genet 21:200-203

Peters MJ, Parker SK, Grim J, Allard CAH, Levin J, Detrich HW 3rd (2018) Divergent Hemogen genes of teleosts and mammals share conserved roles in erythropoiesis: analysis using transgenic and mutant zebrafish. Biol Open 7:bio035576

Popp MW, Maquat LE (2016) Leveraging rules of nonsensemediated mRNA decay for genome engineering and personalized medicine. Cell 165:1319-1322

Qiu M, Liu J, Han C, Wu B, Yang Z, Su F, Quan F, Zhang Y (2014) The influence of ovarian stromal/theca cells during in vitro culture on steroidogenesis, proliferation and apoptosis of granulosa cells derived from the goat ovary. Reprod Domest Anim 49:170-176

Quirk SM, Cowan RG, Harman RM (2006) The susceptibility of granulosa cells to apoptosis is influenced by oestradiol and the cell cycle. J Endocrinol 189:441-453

Ratts VS, Flaws JA, Kolp R, Sorenson CM, Tilly JL (1995) Ablation of bcl-2 gene expression decreases the numbers of oocytes and primordial follicles established in the post-natal female mouse gonad. Endocrinology 136:3665-3668

Regan SLP, Knight PG, Yovich JL, Leung Y, Arfuso F, Dharmarajan A (2018) Granulosa cell apoptosis in the ovarian follicle-a changing view. Front Endocrinol 9:Article 61

Rizzoti K, Brunelli S, Carmignac D, Thomas PQ, Robinson IC, Lovell-Badge R (2004) SOX3 is required during the formation of the hypothalamo-pituitary axis. Nat Genet 36:247-255

Sadraie SH, Saito H, Kaneko T, Saito T, Hiroi M (2000) Effects of aging on ovarian fecundity in terms of the incidence of apoptotic granulosa cells. J Assist Reprod Genet 17:168-173

Santos JM, Menezes VG, Barberino RS, Macedo TJ, Lins TL, Gouveia BB, Barros VR, Santos LP, Goncalves RJ, Matos MH (2014) Immunohistochemical localization of fibroblast growth factor-2 in the sheep ovary and its effects on pre-antral follicle apoptosis and development in vitro. Reprod Domest Anim 49:522-528
Shen M, Liu Z, Li B, Teng Y, Zhang J, Tang Y, Sun SC, Liu H (2014) Involvement of FoxO1 in the effects of follicle-stimulating hormone on inhibition of apoptosis in mouse granulosa cells. Cell Death Dis 5:e1475

Sifer C, Benifla JL, Bringuier AF, Porcher R, Blanc-Layrac G, Madelenat P, Feldmann G (2002) Could induced apoptosis of human granulosa cells predict in vitro fertilization-embryo transfer outcome? A preliminary study of 25 women. Eur J Obstet Gyn Reprod Biol 103:150-153

Sinclair AH, Berta P, Palmer MS, Hawkins JR, Griffiths BL, Smith MJ, Foster JW, Frischauf AM, Lovell-Badge R, Goodfellow PN (1990) A gene from the human sex-determining region encodes a protein with homology to a conserved DNA-binding motif. Nature 346:240-244

Su YQ, Wu XM, O'Brien MJ, Pendola FL, Denegre JN, Matzuk MM, Eppig JJ (2004) Synergistic roles of BMP15 and GDF9 in the development and function of the oocyte-cumulus cell complex in mice: genetic evidence for an oocyte-granulosa cell regulatory loop. Dev Biol 276:64-73

Su YQ, Sugiura K, Eppig JJ (2009) Mouse oocyte control of granulosa cell development and function: paracrine regulation of cumulus cell metabolism. Semin Reprod Med 27:32-42

Sun D, Zhang Y, Wang C, Hua X, Zhang XA, Yan J (2013) Sox9related signaling controls zebrafish juvenile ovary-testis transformation. Cell Death Dis 4:e930

Sutton E, Hughes J, White S, Sekido R, Tan J, Arboleda V, Rogers $\mathrm{N}$, Knower K, Rowley L, Eyre $\mathrm{H}$ et al (2011) Identification of SOX3 as an $\mathrm{XX}$ male sex reversal gene in mice and humans. $\mathrm{J}$ Clin Investig 121:328-341

Takahashi H (1977) Juvenile hermaphroditism in the zebrafish, Brachydanio rerio. Bull Fac Fish Hokkaido Univ 28:57-65

Takehana Y, Matsuda M, Myosho T, Suster ML, Kawakami K, Shin IT, Kohara Y, Kuroki Y, Toyoda A, Fujiyama A et al (2014) Cooption of Sox3 as the male-determining factor on the $Y$ chromosome in the fish Oryzias dancena. Nat Commun 5:4157

Thome RG, Domingos FF, Santos HB, Martinelli PM, Sato Y, Rizzo E, Bazzoli N (2012) Apoptosis, cell proliferation and vitellogenesis during the folliculogenesis and follicular growth in teleost fish. Tissue Cell 44:54-62

Uchida D, Yamashita M, Kitano T, Iguchi T (2002) Oocyte apoptosis during the transition from ovary-like tissue to testes during sex differentiation of juvenile zebrafish. J Exp Biol 205:711-718

Uchida D, Yamashita M, Kitano T, Iguchi T (2004) An aromatase inhibitor or high water temperature induce oocyte apoptosis and depletion of P450 aromatase activity in the gonads of genetic female zebrafish during sex-reversal. Comp Biochem Phys Part A $137: 11-20$

Wang DS, Kobayashi T, Zhou LY, Paul-Prasanth B, ljiri S, Sakai F, Okubo K, Morohashi K, Nagahama Y (2007a) Foxl2 up-regulates aromatase gene transcription in a female-specific manner by binding to the promoter as well as interacting with ad4 binding protein/steroidogenic factor 1. Mol Endocrinol 21:712-725

Wang XG, Bartfai R, Sleptsova-Freidrich I, Orban L (2007b) The timing and extent of 'juvenile ovary' phase are highly variable during zebrafish testis differentiation. J Fish Biol 70:33-44

Wang DS, Zhou LY, Kobayashi T, Matsuda M, Shibata Y, Sakai F, Nagahama $Y$ (2010) Doublesex- and Mab-3-related transcription 
factor-1 repression of aromatase transcription, a possible mechanism favoring the male pathway in tilapia. Endocrinology 151:1331-1340

Watanabe M, Tanaka M, Kobayashi D, Yoshiura Y, Oba Y, Nagahama Y (1999) Medaka (Oryzias latipes) FTZ-F1 potentially regulates the transcription of $\mathrm{P}-450$ aromatase in ovarian follicles: cDNA cloning and functional characterization. Mol Cell Endocrinol 149:221-228

Webster KA, Schach U, Ordaz A, Steinfeld JS, Draper BW, Siegfried KR (2017) Dmrt1 is necessary for male sexual development in zebrafish. Dev Biol 422:33-46

Weiss J, Meeks JJ, Hurley L, Raverot G, Frassetto A, Jameson JL (2003) Sox3 is required for gonadal function, but not sex determination, in males and females. Mol Cell Biol 23:8084-8091

Wilson CA, High SK, McCluskey BM, Amores A, Yan YL, Titus TA, Anderson JL, Batzel P, Carvan MJ, Schartl M et al (2014) Wild sex in zebrafish: loss of the natural sex determinant in domesticated strains. Genetics 198:1291-1308

Xia Y, Papalopulu N, Vogt PK, Li J (2000) The oncogenic potential of the high mobility group box protein Sox3. Cancer Res 60:6303-6306

Xia H, Zhong CR, Wu XX, Chen J, Tao BB, Xia XQ, Shi MJ, Zhu ZY, Trudeau VL, Hu W (2018) Mettl3 mutation disrupts gamete maturation and reduces fertility in zebrafish. Genetics 208:729743
Yan Q, Wang F, Miao Y, Wu X, Bai M, Xi X, Feng Y (2016) Sexdetermining region $Y$-box3 (SOX3) functions as an oncogene in promoting epithelial ovarian cancer by targeting src kinase. Tumor Biol 37:12263-12271

Yang YJ, Wang Y, Li Z, Zhou L, Gui JF (2017) Sequential, divergent, and cooperative requirements of Foxl2a and Foxl2b in ovary development and maintenance of zebrafish. Genetics 205:15511572

Yao B, Zhou L, Wang Y, Xia W, Gui JF (2007) Differential expression and dynamic changes of SOX3 during gametogenesis and sex reversal in protogynous hermaphroditic fish. J Exp Zool Part A Ecol Genet Physiol 307:207-219

Ye J, Fang L, Zheng HK, Zhang Y, Chen J, Zhang ZJ, Wang J, Li ST, Li RQ, Bolund L et al (2006) WEGO: a web tool for plotting GO annotations. Nucleic Acids Res 34:W293-W297

Yin YK, Tang HP, Liu Y, Chen Y, Li GF, Liu XC, Lin HR (2017) Targeted disruption of aromatase reveals dual functions of cyp19a1a during sex differentiation in zebrafish. Endocrinology 158:3030-3041

Yuan J, Zhang Y, Sheng Y, Fu XZ, Cheng HH, Zhou RJ (2015) MYBL2 guides autophagy suppressor VDAC2 in the developing ovary to inhibit autophagy through a complex of VDAC2-BECN1BCL2L1 in mammals. Autophagy 11:1081-1098 